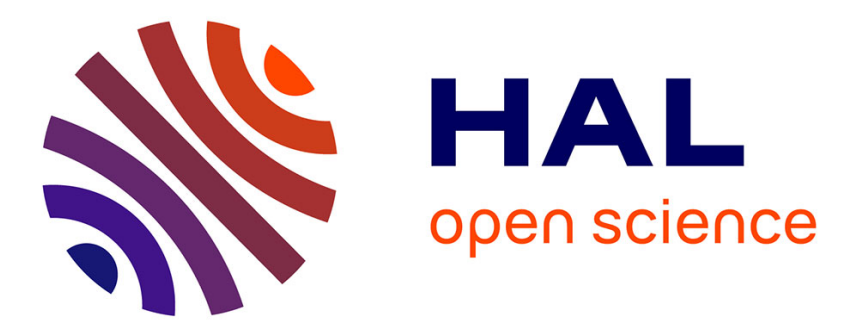

\title{
Light Sources and Lighting: from Technology to Energy Savings
}

Georges Zissis

\section{To cite this version:}

Georges Zissis. Light Sources and Lighting: from Technology to Energy Savings. Jean-Claude Sabonnadière. Low Emission Power Generation Technologies and Energy Management, Wiley \& Sons, pp.333-374, 2013, 978-1-84821-136-0. 10.1002/9781118557976.ch7 . hal-00685707

\section{HAL Id: hal-00685707 https://hal.science/hal-00685707}

Submitted on 1 Jun 2020

HAL is a multi-disciplinary open access archive for the deposit and dissemination of scientific research documents, whether they are published or not. The documents may come from teaching and research institutions in France or abroad, or from public or private research centers.
L'archive ouverte pluridisciplinaire HAL, est destinée au dépôt et à la diffusion de documents scientifiques de niveau recherche, publiés ou non, émanant des établissements d'enseignement et de recherche français ou étrangers, des laboratoires publics ou privés. 


\section{Light Sources and Lighting: from Technology to Energy Savings}

\subsection{Lighting in the past and today}

Man has always desired to carry on with his normal life after nightfall. Subject to the rhythms and hazards of natural light sources, he very quickly tried to replace the natural light with artificial sources.

For centuries, human society had to satisfy itself with the use of fire to generate light. Man thus, unconsciously, discovered one of the two processes of artificial light generation: incandescence. However, phenomena such as phosphorescence and fluorescence have shown that material was able to generate light without necessarily increasing its temperature. Man also desired to imitate other "natural" light sources such as fireflies, phosphorescent minerals or lightning. These sources generate light thanks to the luminescence ${ }^{1}$ phenomena. This second process is much more efficient than incandescence, but was previously not exploitable because these sources were either hazardous or difficult to control. Furthermore, the energy efficiency was not up to date. However, during this period, man always had a dream of putting lightning into a bowl to give out light. It was only during the 19th century that this dream came true. The English chemist Sir Humphry Davy (1778-1829) discovered the electric discharge phenomena. In 1802, he tried to reproduce in his laboratory Franklin's experiment demonstrating the electric nature of lightning. He noticed the

Chapter written by Georges ZISSIS.

1. The German scientist Wiedemann suggested, in 1888, calling this cold light emission "luminescence" and to eventually clarifying its generation mode by means of a prefix (bioluminescence, electroluminescence, thermoluminescence, chemiluminescence, etc.). 
appearance of an electric discharge emitting an intense light between two carbon electrodes connected to an electric battery. He did not use this new light source because it was too unstable and required a reliable energy source. Thanks to the development of chemical batteries between 1830 and 1840, experiments on the light generated by electric arcs were conducted, and in the period 1850-1870 many lamps appeared. However, chemical batteries were too expensive for a significant economic development. In the 1870s, less expensive and more practical batteries allowed the Russian Paul Jablochkoff (1847-1894), who was in Paris at that point, to patent the "electric candle" in 1876. He then put this on the market in France and the UK (Figure 7.1). It consisted of two vertical and parallel carbons, brought closer, and insulated except at their tips. The insulating layer thus burns at the same time as the carbon does, and a spark shines at the tips of the two pencils. This electric arc was used for the external lighting (urban) and the internal lighting of some factories. Furthermore, in order to be used in an easier way, a more compact form was given to these new artificial light sources known as "lamp".

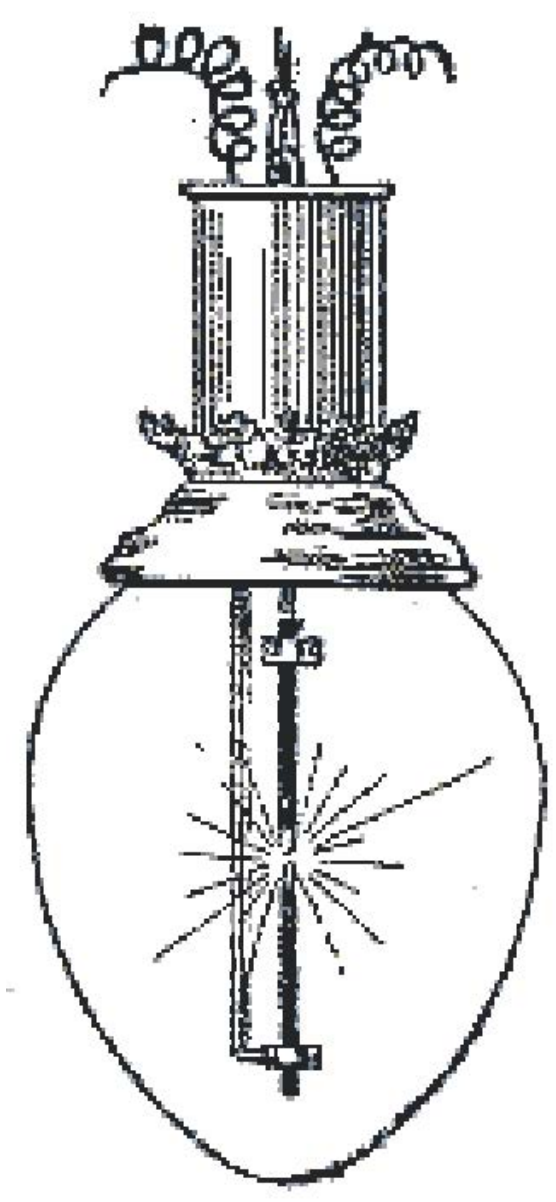

Figure 7.1. The Jablochkoff "electric candle", an 1876 patent. This lamp lit up Paris, especially Opera Avenue, during the 1878 Exhibition Universelle 
At the same time, in the USA, the arc lamp was used for lighting shop windows and some small installations. The reliability and the efficiency of the electric arc were gradually improved, particularly due to the works of Rookes Evelyn Bell Crompton (1845-1940), by the use of high purity carbons and accurate regulators which reduced light fluctuations.

Finally, the introduction of enclosed space arcs in 1893 by the American engineer L.B. Marks represented a major development for discharge lamps. In a closed lamp, the arc was confined in glass bowls, which avoided excessive carbon consumption due to the air flow. The maintenance costs was then reduced, but the power required to the lamp operation was greater.

Arc lamps dominated the lighting market until the invention of the incandescence lamp by Thomas Edison in $1878^{2}$. Very quickly, the Edison Lamp replaced the arc lamp despite its more than mediocre efficiency, but once more, the energy efficiency was not the problem. Indeed, the first incandescent lamps generated a light quantity equivalent to 16 "candelas" whereas the arc lamps of the same period reached 2,000 to 4,000 candelas ${ }^{3}$. The success of the incandescent lamp is partly justified by three factors:

1) the incandescent lamp was well easier to mass produce;

2) its lifetime was much higher than that of the existing arc lamps;

3 ) it required very little maintenance (arc lamp electrodes had to be replaced very frequently).

However, the decisive factor for this invention coming to dominate the market was a forewarning of sustainable development: Edison very quickly noticed that to impose its invention, he had to "democratize" it. Thus, to reach this goal, electricity had to be brought to the individuals. Edison thus created the first electricity generation and distribution company. This is one of the first examples of a "systemic" vision of history. The Edison Company still exists to day; it is known under the name of the giant General Electric.

2. We recall that Edison "invented" and developed the incandescent lamp at the same time as his competitor Swan, but Edison knew how to market his invention, and above all he developed the electric distribution system. However, one of the true pioneers of the electric incandescent lamp is presumably Heinrich Gœbel who in 1854 first had the idea of making a carbon filament lamp, in order to illuminate his clock and watch shop in New York at night.

3. The ISO unit "candela" was afterwards defined as being the light intensity emitted by an "English standard candle". Let us recall that an "English standard candle" should be visible, in clear weather, at a distance of $27 \mathrm{~km}$ ! 


\subsubsection{Present-day lamp families}

Increasingly present in our activities, lamps and lighting have seen continuous development over the centuries. The use of electricity has been a revolution in this field. However, all the sources generating artificial light from electricity always use two basic properties, incandescence and luminescence, which had already been identified by prehistoric man.

Looking closer we find traditional source families (incandescent bulbs and discharge lamps), but also the electroluminescent diode families, which have entered the lighting world since over the last few years to a massive extent ${ }^{4}$, along with some new products such as aggregate lamps and field emission lamps. Figure 7.2 presents, in a synthetic way, the different source families likely to be used for light generation or to provide sign post functions.

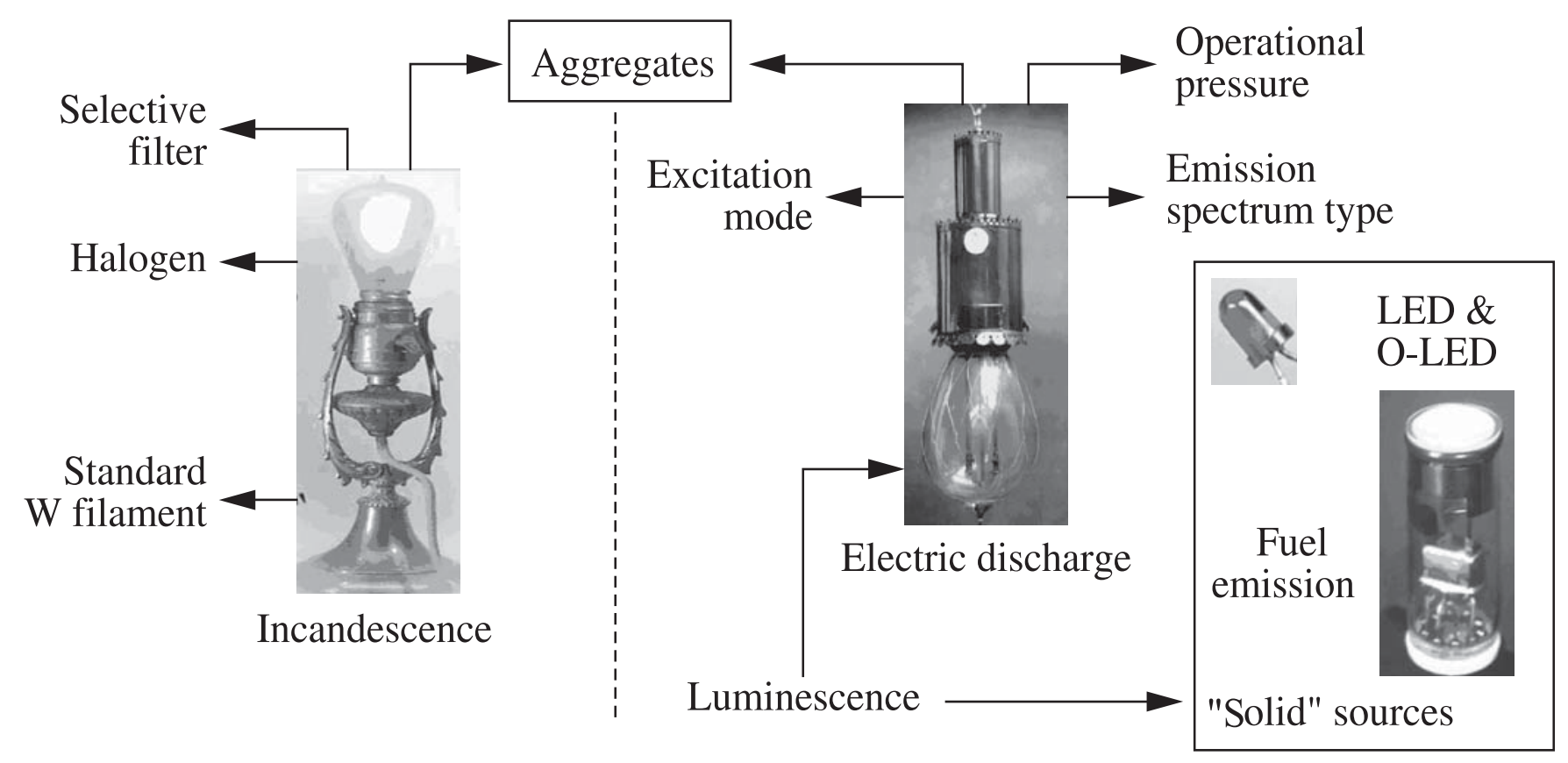

Figure 7.2. The lamp families

Today, the light sources represent a considerable market; the number of electric lamps operating on Earth is estimated at some 33 billion, whereas annual production exceeds 16 billion units. Table 7.1 outlines these data.

4. Today electroluminescent diodes are replacing the standard semiconductor diodes and their organic versions known as O-LEDs. 


\begin{tabular}{|c|c|c|c|}
\hline Lamp type & $\begin{array}{c}\text { Annual requirements } \\
\text { (billion units) }\end{array}$ & $\begin{array}{c}\text { Lifetime } \\
\text { (years) }\end{array}$ & $\begin{array}{c}\text { Existing } \\
\text { (billion units) }\end{array}$ \\
\hline Incandescence & 11.5 & 1 & 11.5 \\
\hline Halogen & 0.8 & 2 & 1.6 \\
\hline Fluorescent & 3.2 & 5 & 16.0 \\
\hline Compact Fluo & 0.6 & 5 & 3.0 \\
\hline High pressure & 0.2 & 3 & 0.6 \\
\hline Total & $\mathbf{1 6 . 3}$ & & $\mathbf{3 2 . 7}$ \\
\hline
\end{tabular}

Table 7.1. The lamp market in the world

\subsubsection{The economic, environmental and energy impact of lamps}

From the energy point of view, lighting consumes more than 2,651 TWh electric energy per year. This represents approximately $19 \%$ of the total world electricity generation $^{5}$ [IAE 05]. It also represents an annual bill of more than 200 billion euros for the consumer [MIL 02]. The situation is different from one country to another. Thus, the energy consumption for the lighting of a western country varies between $7 \%$ and $15 \%$ of its energy generation (with a single case, the USA, where this is around 20\%).

More precisely, France consumed 41 TWh for lighting in 1999. A little less than two thirds of this energy ( $60 \%$ of the total) is used by the tertiary area. Road and public lighting consumes $10 \%$ of the total, whereas $30 \%$ of the energy is absorbed by domestic lighting. However, it must be noted that this last area has seen its consumption increase threefold in the past two decades ${ }^{6}$. In the USA, the electric energy consumption for lighting in the year 2000 reached $659 \mathrm{TWh}$, which represents $19 \%$ of the electric energy generated in the country (in absolute value, this energy is equivalent to the combined electricity generation of France and Italy). Here again, tertiary lighting prevails in this consumption as shown by Figure 7.3. It must be made clear however that the major part of this energy is consumed by incandescent lamps: 46\% [SCO 02]. Figure 7.3 compares the French and American situations.

5. This quantity of electricity represents the equivalent of $1-2 \%$ of the primary energy used on our planet during one year.

6. Domestic lighting energy consumption in France: 5 TWh in 1979, 14 TWh in 1999. 


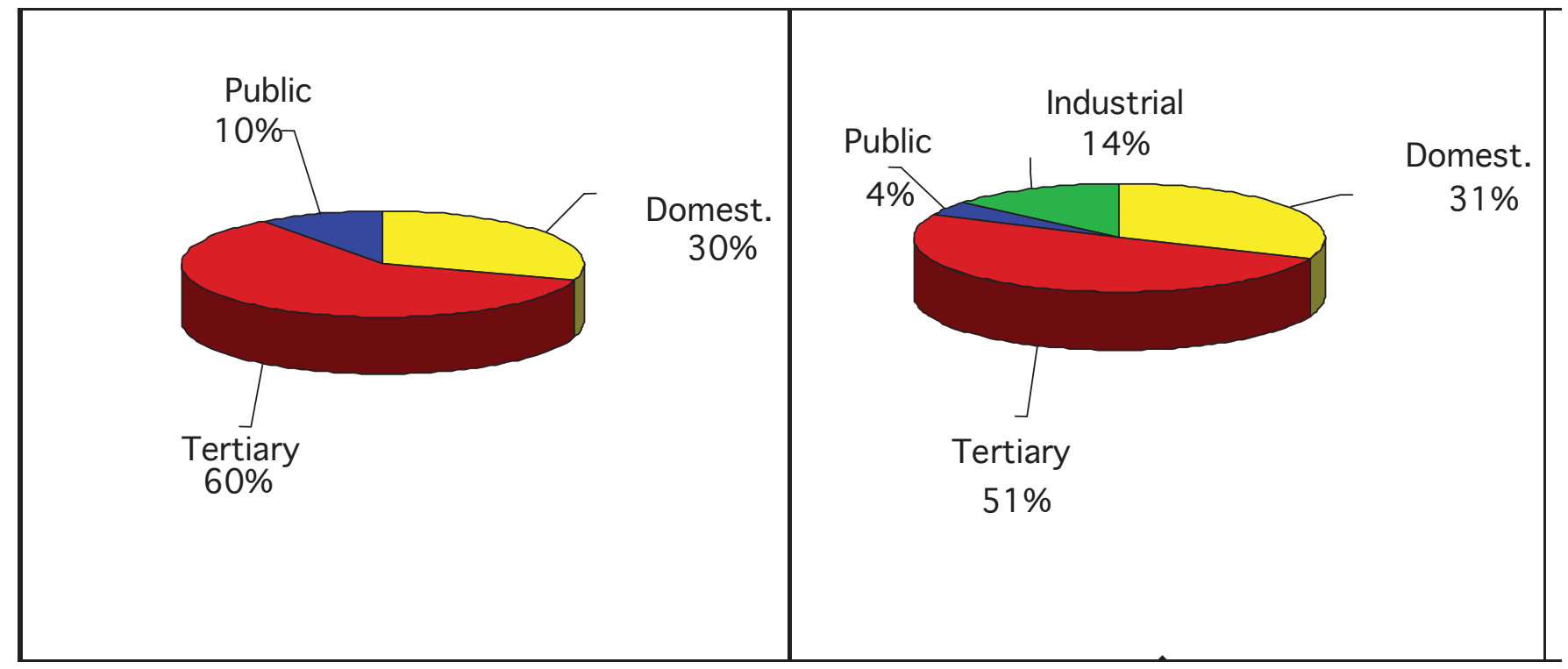

a)

b)

Figure 7.3. Comparison of energy consumption dedicated to lighting in 1999 a) in France: 41 TWh and b) in the USA: 650 TWh

As far as the developing countries are concerned, the situation is different. Lighting represents the major part of their electric consumption today: $30 \%$ for Tunisia, nearly $40 \%$ for Madagascar and up to $86 \%$ for Tanzania (champion of all categories in this field). Here domestic lighting prevails. This situation is easily understandable since light is a basic need for man, and, of course, as soon as electrification progresses, the population takes profit from it by first installing lamps. On the other hand, in these countries, the cost of lamps is a major factor in the choice of the type of light source. Thus, incandescent lamps dominate the market because "low consumption" lamps are often not available. Once again energy efficiency is neglected due to other considerations...

\begin{tabular}{|c|c|c|}
\hline \multirow{2}{*}{ Pollutant } & $\begin{array}{c}\text { Fluorescent Lamp } \\
\mathbf{3 6 ~ W}\end{array}$ & $\begin{array}{c}\text { Incandescent Lamp } \\
\mathbf{6 0} \mathbf{~ W}\end{array}$ \\
\hline $\mathrm{Hg}$ & 0.64 & 4.45 \\
\hline $\mathrm{Pb}$ & 19 & 136 \\
\hline $\mathrm{Cu}$ & 26 & 185 \\
\hline $\mathrm{No}_{\mathrm{x}}$ & 21,700 & 152,000 \\
\hline $\mathrm{SO}_{2}$ & 16,300 & 114,000 \\
\hline
\end{tabular}

Table 7.2. Emission of toxic substances due to the required energy generation following the production of 1 lumen during 1 hour, expressed in $n g /(\mathrm{lm} / \mathrm{h})$ 
The electric energy generation to satisfy the lighting needs of man has inevitably led to environmental pollution. It is thus estimated that each year, some 1,700 million metric tons of $\mathrm{CO}_{2}$ accompany this energy generation, contributing to the greenhouse effect. At the same time, other toxic substances are also produced. Table 7.2 gives an estimation for two types of lamps generating the same light quantities (in lumens).

Furthermore, lamps contain rare and often toxic ( $\mathrm{Hg}, \mathrm{Cd}$, rare earth, etc.) materials. They also contain radioactive materials $\left(\mathrm{Th},{ }^{98} \mathrm{Kr}\right.$ ), and their ferromagnetic ballasts contain lead. Thus, at the end of their lives the materials in the lamps may pour out into nature. For instance, the majority of lamps, except incandescent lamps, contain mercury. This is why, in the USA, to produce some 750 million fluorescent tubes each year, 2.5 tons of mercury are used. In other countries, such as France, about 80 tons of waste contaminated with mercury are collected each year. A new European regulation, effective since 1st January 1998, imposes that discharge lamps coming to the end of their life become "final" waste and that they are reprocessed before storage in special dumps (called "terminal" dumps). Storage in such a dump costs about 200 euros per ton of processed waste. Finally, regarding the quantity of toxic material in the lamps, there has been since 2003 a new European regulation, "RoH - Removal of Hazardous wastes", [EUP 03]. This regulation limits the amount of mercury in a discharge lamp.

The lamp industry is under development. The annual expansion of this area is around $0.9 \%$. In absolute value, this rate seems low but it has remained stable for about the last 20 years, which makes the lamp industry one of the four industrial areas with the highest growth rate over the last two decades. This is why Japan, which represents today $20 \%$ of the world market, has experienced during the last five years a production growth of $3 \%$ to $8 \%$ per year and an annual sales increase of $9.7 \%$ (on average during the last ten years).

The total turnover of the light sources industry is about ${ }^{7} 14$ billion euros per year. However, the lamp industry and the lamp market have a true specificity: three major actors concentrate most of the activity: Philips Lighting, General Electric Lighting and Siemens-Osram. Some details are given below:

- Philips Lighting is the world number 1 in lighting. In particular, it holds half of the market share in Europe. The sales in 2005 rose up to 4.8 billion euros $^{8}$, an increase of $6.6 \%$ with respect to the preceding year. The company employs 45,650 people, with an increase of 1,500 people since 2004 .

7. This turnover only concerns lamps and does not include either the electronic ballast area or the light fittings. The total turnover of the "lighting" area is probably 5 times higher.

8. Philips Lighting represented, at the first quarter of 2004, $15.7 \%$ of the Philips industry group turnover. 
- The German company Osram, a subsidiary of the Siemens Group, is a company with 36,000 employees in 58 countries, with a turnover of 4.2 billion euros. With a profit of $10.8 \%$ of its turnover, in 2005 Osram reached the "highest level" in 5 years. Since its purchase of GTE-Sylvania (USA) in 1990, the USA, with $44 \%$ of the sales, has become the priority target for Osram, followed by Europe $(37 \%)$ and Asia-Pacific (16\%).

- General Electric Lighting is the American number 1 and represents 50\% of the market share in the USA. Its turnover is about 3 billion euros. For the last 10 years GEL's preferred target has been Europe and its market. To reach this goal, GEL has made many acquisitions: the Hungarian Thungsram, the British Thorn EMI, the Italian Sivi, and the German Linder Licht. Investments over the last 6 years have exceeded 750 million dollars.

These three major companies represent by themselves a turnover of 12 billion dollars. This type of structure is called an "oligopoly". All the other companies, of which Sylvania Lighting International and Matshushita are the largest, represent a turnover of only 2 billion dollars (this represents for these companies a turnover 10 times lower than the "big three"). It remains that many national factories (which are small or middle size) conserve a market and know-how, either in the source area or in the equipment area. On the other hand, the "lighting" market (first installation and maintenance) still remains in the hands of "light designers" (engineers, architects, etc.) often linked to the principal parties such as the government or the communities.

\subsection{Light sources and energy conversion}

The previous sections largely illustrate the impact of lighting on the national and international energy level. On the other hand, we know today that the world population is growing at a steady rate and despite everything the quality of life of the population is progressing. Furthermore, as shown by Mills in his works [MIL 02], there exists a quasi-linear relationship between the internal gross product and the per capita lighting energy consumption. Moreover, electrification is progressing and new areas in the world are lit by means of electricity ${ }^{9}$. Taking into account these three statements, we know today for sure that the lighting needs of humans will continuously grow; a factor of about 2 is expected in the next two decades.

How can we satisfy this growth without the demand for energy increasing in the same proportion?

9. In 2004, more than 1.7 billion people on Earth did not have access to electric lighting (this was 2 billion in 1996, according to the World Bank). 
A first answer to this question would be to put increased efficiency light sources onto the market. However, as we will explain later on, the answer is a lot more complex than this first approximation ${ }^{10}$. At this stage, however, we will voluntarily limit our discussion to the question of light source efficiency. For this discussion, it is important to separate the concept of "energy efficiency", $\eta$, expressed in $\%$, from the concept of "light efficiency", $\eta_{\text {lum }}$, expressed in lumens per watt. Thus, for a light source absorbing an electric power $P_{i n}$ (expressed in watts), which emits a radiated power $\mathrm{P}_{\mathrm{r}}$ (also expressed in watts), the energy efficiency is traditionally defined as the ratio of these two quantities:

$$
\eta=\frac{P_{r}}{P_{i n}} \times 100(\%)
$$

However, the energy emitted by the source presents a spectral distribution $P_{r}(\lambda)$, which characterizes, amongst other things, the emitter body and the emission ${ }^{11}$ process. This distribution may extend to a very large wavelength range $\lambda$, but only the wavelengths of the "visible" electromagnetic spectrum (located between $360 \mathrm{~nm}$ and $780 \mathrm{~nm}$ ) are perceptible by our visual system; the others do not contribute to the vision process. On the other hand, the sensitivity of our visual system depends on the wavelength and, as we will see later, it also depends on the light quantity. Figure 7.4 shows the standard response, $V(\lambda)$, of the human eye.

Under these conditions, instead of the total radiated power, light specialists use the notion of light flux, $\Phi$, expressed in lumens $(1 \mathrm{~m})$. This quantity better represents the "useful" light emitted by the source. The light flux is then defined as:

$$
\Phi=k \int_{360}^{780} P_{r}(\lambda) V(\lambda) d \lambda
$$

in which $\kappa$ is the normalizing factor of the curve $V(\lambda)$, defined by the International Lighting Commission (ILC) as being equal to $683 \mathrm{~lm} / \mathrm{W}$. Using the light flux defined above, the light efficiency of a light source is given by the ratio of the light flux (in lumens) over the absorbed power (in watts) and is expressed in lumens per watts $(\mathrm{lm} / \mathrm{W})$ :

$$
\eta_{\text {lum }}=\frac{\Phi}{P_{\text {in }}}
$$

10. Some studies, taking into account man's increased demand for lighting, show that by simply using the existing sources in a reasonable way, we could save between 10 and $15 \%$ of the consumed energy in the next decade; but others give opposite results...

11. Incandescence generates a continuous spectrum (close to a "black body" spectrum), whereas luminescence is characterized by a discontinuous spectrum (rays or spectral band). 


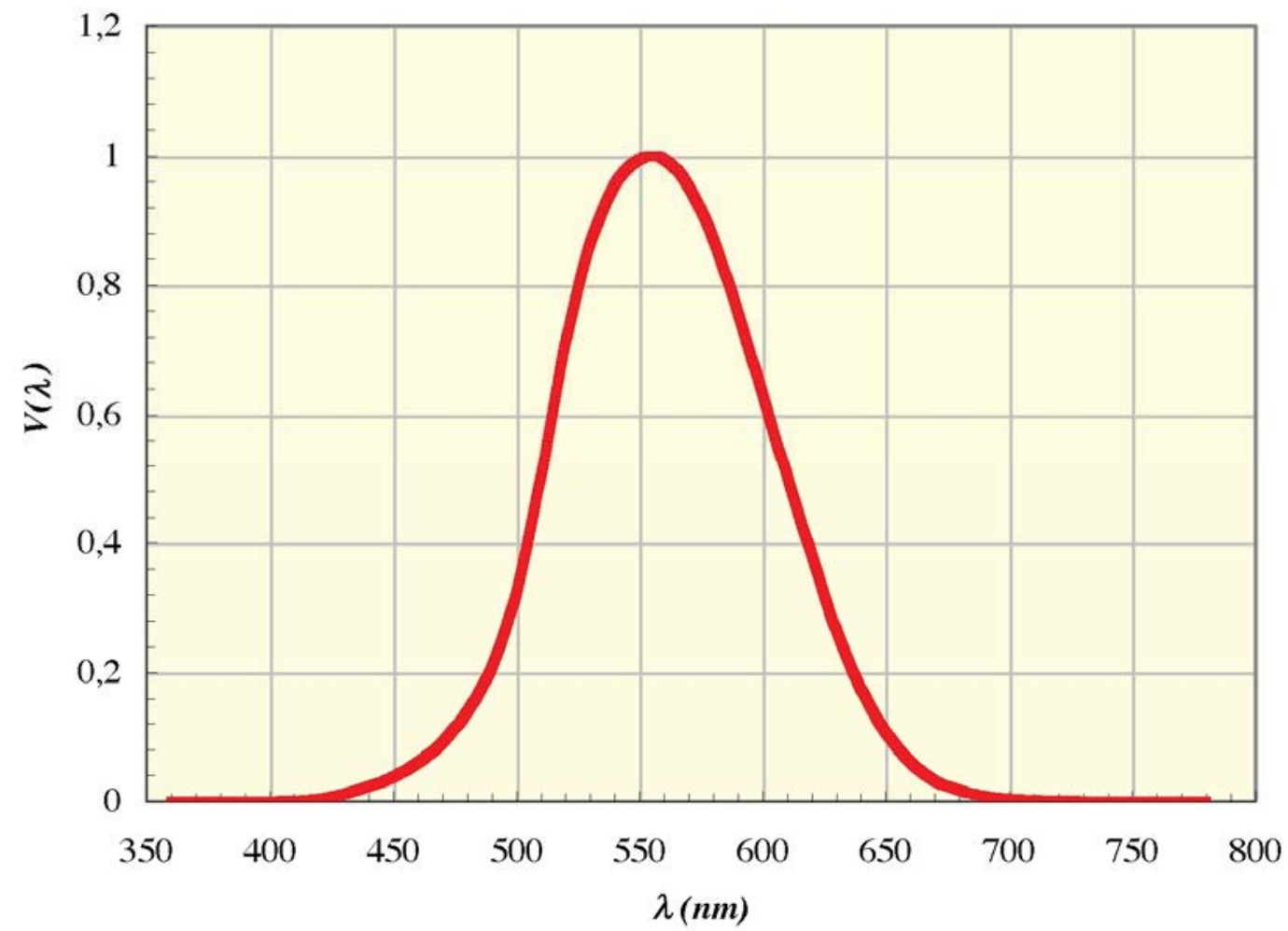

Figure 7.4. Standard response of the human eye. This curve shows the "photopic" eye response. The standard coefficient is defined by the ILC and is equal to $683 \mathrm{~lm} / W$

\subsubsection{The thermodynamic limit of white light generation}

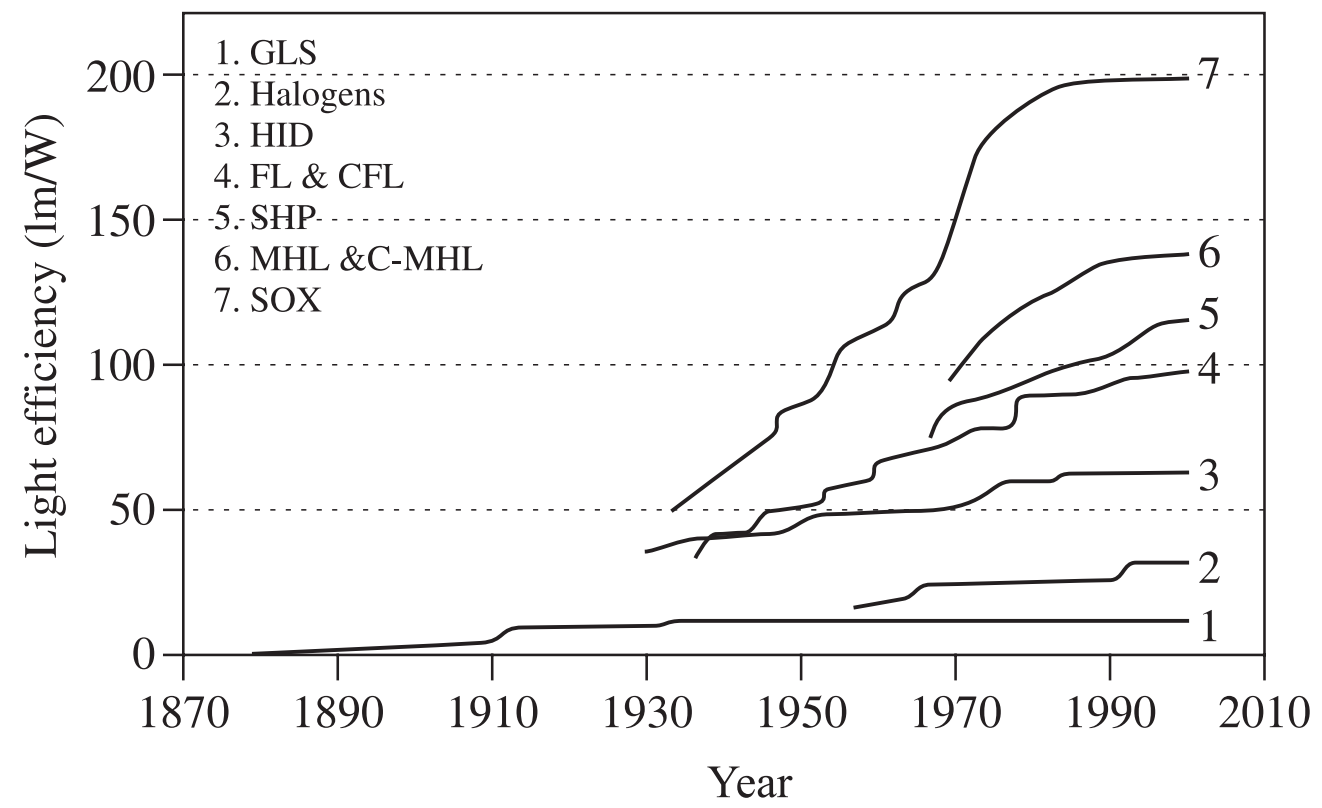

Figure 7.5. Evolution of the efficiency of electric lamps used for general lighting. GLS: incandescent lamps, HID: mercury high pressure lamps, FL \& CFL: compact and lineic fluorescent lamps, SHP: sodium high pressure lamps, MHL \& C-MHL: metallic hydride high pressure lamps with a ceramic and silica envelope, SOX: sodium low pressure lamps (monochromatic yellow light) 
Currently, despite all the science and technological advances in the field of lamps, the maximum radiative efficiency of lamps for the production of white light has been stagnating for at least two decades, around $120 \mathrm{~lm} / \mathrm{W}$, as seen in Figure 7.5 .

On the other hand, this graph clearly shows that the light efficiencies of "headlight" products ${ }^{12}$ in the lamp industry reached their limit a long time ago. The question raised is the following: has the lamp industry reached a sort of "thermodynamic limit"?

To answer this question, let us try to determine what a reasonable higher limit of lamp efficiency generating white light of a "good quality" could be, with a color temperature, $T_{C}$, ranging between $3,000 \mathrm{~K}$ and $6,500 \mathrm{~K}$ and a good color rendering (color rendering index, $\mathrm{CRI} \geq 80$ ).

To obtain light perceived as "white", it is necessary to have, at least one emitter which allows a balanced excitation of the photo-receivers (more precisely, the three cone families each offering a maximum sensitivity centered around the red, green and blue colors) present in the fovea of the human eye ${ }^{13}$. Thus the desired "white" light can be obtained either by a radiation, the spectrum of which covers all the visible range of the spectrum (this is the case of the Sun or an incandescent body), or, thanks to the physiology of our visual system, by a combination of blue, green and red colors (this is the case of color TV) or else, by a combination of blue and yellow.

The Sun's radiation or incandescent radiation may be linked to "black body" radiation. They have similar properties, particularly regarding their dependency on the temperature of the emitting body. This is why the "black body" will be taken as the reference starting point. At temperature $T_{C}$, the radiation spectrum of the "black body" presents at wavelength $\lambda$, a spectrum brightness $L_{C N}\left(\lambda, T_{C}\right)$ given by the Planck relationship, which is the absolute higher limit for the radiation emitted around this wavelength. Integrating the Planck relationship, we can easily deduce the radiation fraction corresponding to the visible part of the visible spectrum. Thus, Figure 7.6 shows the "weight" of the visible spectrum in the total emission of the black body with respect to its surface temperature. We note that this fraction, in any

12. This graph does not include electroluminescent diodes (ELD). This omission is voluntary; electroluminescent diodes are not currently mature enough to be used in an intensive manner for general lighting; they are instead devoted to signaling and to decorative lighting. However, ELDs may not be ignored in the near future; a detailed discussion will be presented later in this chapter.

13. The fovea is the retina area located in vision direction; this area has a very limited surface area, but it presents the highest concentration of photo-receivers (cones essentially) and is reponsible for "accurate" and for "colored" vision. 
case, cannot exceed half of the total radiated power. This is obtained for a surface temperature of about $5,000 \mathrm{~K}$.

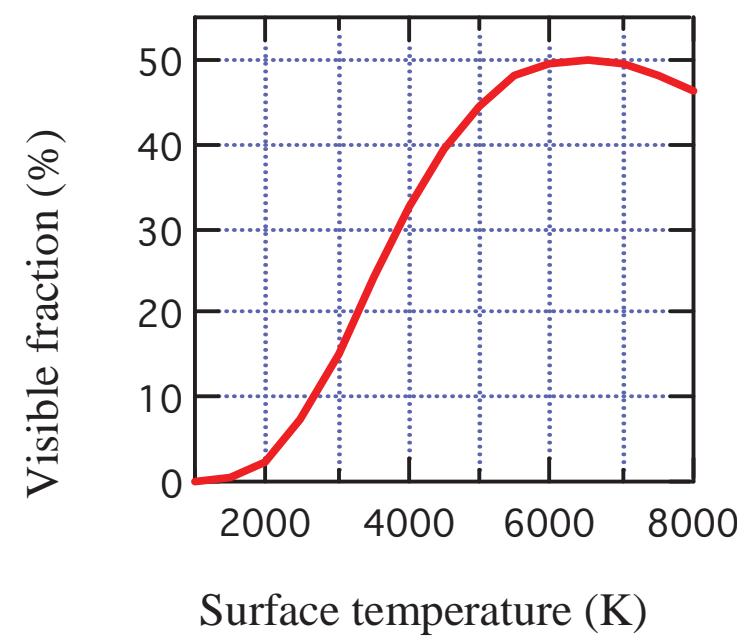

Figure 7.6. The "weight" of the visible spectrum in the total emission of the black body with respect to its surface temperature

However, the "black body" is only a theoretical concept. In fact, the brightness $L\left(T_{C}, \lambda\right)$ of a real body, when it can be characterized by a unique temperature, is linked to the black body emission by a quantity, the emissivity, which is always smaller than 1 . The emissivity, $\varepsilon\left(T_{C}, \lambda\right)$, is specifically a function of the body characteristic temperature $T_{C}$ and of the considered wavelength $\lambda$. We will then speak of "gray bodies", the brightness of which $L\left(T_{C}, \lambda\right)$ will be written:

$$
L\left(T_{c}, \lambda\right)=\varepsilon\left(T_{c}, \lambda\right) L_{C N}\left(T_{c}, \lambda\right)
$$

Thus, for an incandescent lamp, the light quantity radiated in the narrow visible spectral band generally depends on the radiator temperature. The lamp filament is made of metal and is heated by the Joule effect when an electric current flows through it. The maximum temperature is then imposed by the fusion point of the metal used. Tungsten is the metal with the highest fusion temperature at $3,410^{\circ} \mathrm{C}$, and this why it is used in lamp manufacturing. In practice, the mechanical and thermodynamic requirements limit the temperature to $2,700-3,000^{\circ} \mathrm{C}$. At this temperature, Wien's law says that the major part of the radiation emitted by the filament is in the infrared portion of the spectrum $(\lambda>780 \mathrm{~nm})$. Under these conditions, less than $25 \%$ of the total radiation is found in the visible range. This leads to a global energy efficiency of about $10 \%$ and a light efficiency of $14 \mathrm{~lm} / \mathrm{W}$. It seems difficult to make this any better with an incandescent body, except perhaps by replacing the metallic filament with a semiconductor (some attempts have been made, but the result is far from being exploitable). But, as already discussed, the emission of a continuous spectrum is not the only solution to obtain white light. 


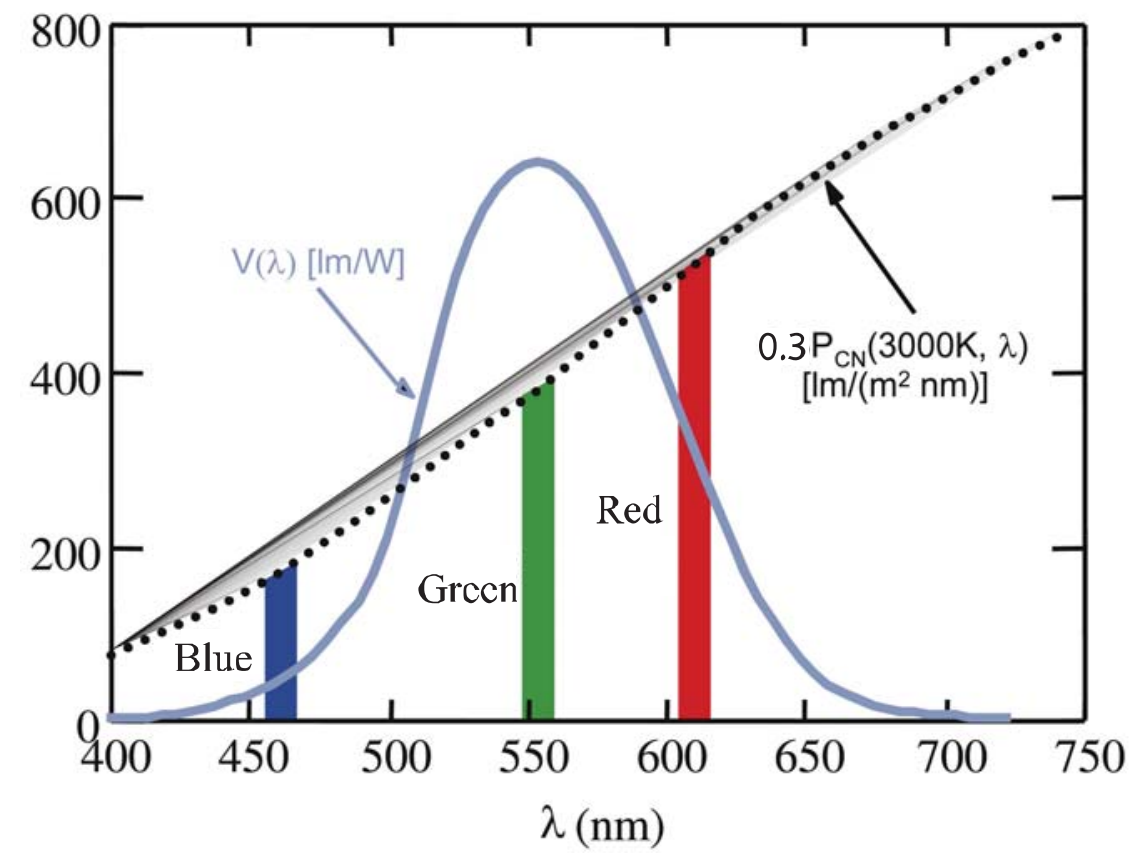

Figure 7.7. White light can be obtained by combining three photons (blue, green and red). A lamp capable of emitting these three photons, such as a black body at $3000 \mathrm{~K}$ (black dashed line curve), would have a light efficiency of $300 \mathrm{~lm} / \mathrm{W}$ !

It seems that the best compromise between efficiency and quality would be the use of three emissions, blue, green and red, located in the respective sensitivity maximum of each three cone families which cover the fovea of our eye. Figure 7.7 shows the principle of a source which would radiate these three wavelengths only, such as a black body at $3,000 \mathrm{~K}^{14}$.

The radiation efficiency can be computed using relations [4.2], [4.3] and Planck's law:

$$
\eta_{\text {ray }}^{\max }=\frac{\kappa \sum_{i=1}^{3} P_{C N ; i}\left(T_{c}=3000 K, \lambda_{i}\right) V\left(\lambda_{i}\right)}{P_{\text {in }}} \quad \lambda_{i}=\left\{\begin{array}{l}
436 \mathrm{~nm}(\text { blue }) \\
546 \mathrm{~nm}(\text { green }) \\
700 \mathrm{~nm}(\text { red })
\end{array}\right.
$$

$P_{C N ; i}\left(T_{C}, \lambda_{i}\right)$ represents the power of each of the three photons according to Planck's law. A numerical application leads to $300 \mathrm{~lm} / \mathrm{W}^{15}$. This value is three times higher than the best efficiency that can be achieved today. It thus seems realistic to declare that it would be possible, taking into account a global conversion efficiency

14. This lamp, despite its efficiency, would have a very bad color rendering because of its quite "poor" spectrum.

15. This value is the light efficiency of the electricity into white light conversion; it does not include the losses of the global system (mainly losses in the lamp supply circuit). 
of the system, around $65 \%$, to target light efficiencies of about $200 \mathrm{~lm} / \mathrm{W}$. The challenge is significant, and the associated energy savings (at constant light flux) are in proportion!

\subsubsection{Lamp technology and associated challenges}

How can we achieve the goal of the previous section? Today the answer is not known, but we are sure this is not the only answer. The efficiency and quality of each of the lamp families may be improved. Figure 7.5 shows hope for an evolution, each family having its own objectives and challenges. However a "revolution" in the lighting field is not impossible: electroluminescent (mineral and organic) diodes may be one "revolution", but discharge lamps have not had their last word... This section is dedicated to the description of these challenges.

\subsubsection{Incandescent lamps}

In today's incandescent lamps, the tungsten radiator (filament) is heated by the Joule effect. It is a very dense medium, the power density of which is high, and the (surface) emission presents a strong brightness. Its radiation is continuous and approximately follows (in the visible) the "gray" body law at the filament temperature. However, it is not possible to raise the temperature too much because the local filament evaporation and its recrystallization reduce the lamp lifetime very quickly by breaking the filament. This lifetime mainly depends, through these two phenomena, on the voltage, switching on and off, the vibrations, the temperature field around the lamp, etc. The other consequence of evaporation is the darkening of the bulb. This evaporation is controlled by a rare gas which reduces the speed of evaporation. However, the large size of the bulbs limits the rare gas pressure to a value close to atmospheric pressure. The tungsten-halogen cycle makes it possible, to eliminate the tungsten deposit on the glass surface in halogen lamps. The dimensions of the bulbs may then be reduced and the rare gas pressure may be considerably increased, which will limit the evaporation. This saving in the evaporation can be used directly, in terms of lifetime, or it may be transformed, at a constant lifetime, into an increase in temperature and thus in light efficiency. These trade-offs are made according to the use. For halogen lamps in general lighting, the color temperature has been raised to $3,000 \mathrm{~K}$ for a 2,000 h lifetime. Under these conditions, the light efficiency is limited to 20 to $25 \mathrm{~lm} / \mathrm{W}$, which is however higher than the 12 to $14 \mathrm{~lm} / \mathrm{W}$ of the ordinary incandescent lamps. There have been attempts to change the emissivity of the radiator, but so far these have proved unsuccessful.

Attempts to replace the tungsten filament with semiconductor materials with a high fusion point are currently being studied, but the technology seems to be very 
complex. Light efficiency may also be increased by reflecting part of the infrared radiation generated by the lamp towards the filament. This can be done by laying (approx. 46) CVD thin layers onto the bulb surface. They behave like an interferential filter. The results are promising, but this method remains expensive at the present time.

However, even though this family seems to have exhausted its potential for evolution, taking into account the range of use of the lamps, their low cost and their excellent color rendering index (they are given by definition CRI $\approx 100$ ), are still attractive. However, many countries have decided to ban them from the market over the next few years.

\subsubsection{Discharge lamps}

Although the electric discharge lamp, made for the first time in 1814 by Sir H. Davy and M. Faraday, was the first plasma application, it took more than half a century before a commercial achievement. Today, thanks to a better understanding of the physical processes that govern their operation, discharge lamps have considerably improved since their first appearance.

A discharge lamp is made of a sealed and transparent (or translucent) burner that contains the discharge gaseous medium, letting the radiation they want to use escape at the same time. This container, the shape and dimension of which varies greatly, contains a gas mixture and/or metal vapors, capable of radiating in the range of the desired wavelength. The excitation of the mixture is performed either by the flow of an electric current between two electrodes, or by injecting a high frequency electromagnetic radiation (radiofrequencies, microwaves, etc.) into the bulb. However, since the current-voltage characteristic of a discharge is negative or weakly positive (in the case of high pressure lamps), an impedance is necessary to stabilize the discharge current.

The active element pressure may lie between a few dozen and a few million Pascal. We tend talk about low pressure or high pressure (LP and HP respectively) lamps. This parameter will thus be used to discuss the different lamp families and the associated challenges.

\subsubsection{1. "High pressure” discharge lamps}

The "high pressure" lamps operate under pressures from 1 to several hundred bars (200 bars for the UHPTM lamp used in video projectors). It must be noted that most of the current HP lamps use mercury to control the electronic mobility in the plasma. 
For these lamps, we generally consider that the thermodynamic equilibrium is approximately obtained locally. Under these conditions, for a given discharge, the medium is characterized well enough by its central temperature $T_{0}$ and its radial distribution. In the majority of the cases we are interested in, the radial distribution of the temperature follows a monotonous profile of the "parabolic" type:

$$
T(r)=T_{0}-\left(T_{0}-T_{w}\right)\left(\frac{r}{R}\right)^{\beta}
$$

in which $T_{w}$ is the bulb temperature, $R$ the lamp radius and $\beta$ the "profile" parameter.

Under these conditions, the radiation brightness approaches the black body brightness at the temperature $\mathrm{T}_{\mathrm{C}}$ in the spectral regions where the optical thickness is greater than a few units. We are now in situations which meet the above principles but with central temperatures between $4,000 \mathrm{~K}$ and $6,000 \mathrm{~K}$ and with a certain possibility of acting on the emissivity by selecting the radiating bodies (active elements: mercury, sodium, thallium, dysprosium, etc.). The light efficiencies obtained are currently between $50 \mathrm{~lm} / \mathrm{W}$ and $110 \mathrm{~lm} / \mathrm{W}$. On the other hand, the medium, also less dense than a solid, still allows significant volume emissions $\left(10^{4} \mathrm{~lm} / \mathrm{cm}^{3}\right)$.

The best known "high pressure" lamps are:

- high pressure mercury lamps $\left(\mathrm{T}_{\mathrm{C}} \approx 3,000-4,500 \mathrm{~K}, \mathrm{CRI} \approx 50, \eta_{\mathrm{rad}} \approx 50 \mathrm{~lm} / \mathrm{W}\right)$, used for lighting large areas (warehouses) and for urban lighting;

- high pressure sodium lamps $\left(\mathrm{T}_{\mathrm{C}} \approx 2,100-2,300 \mathrm{~K}, \mathrm{CRI} \approx 15-60, \eta_{\mathrm{rad}} \approx 50-\right.$ $120 \mathrm{~lm} / \mathrm{W}$ ), devoted to road and urban lighting and to emphasize monuments;

- metallic halogen lamps with a polycrystalline aluminum oxide or silica envelope $\left(\mathrm{T}_{\mathrm{C}} \approx 3000-6000 \mathrm{~K}, \mathrm{CRI} \approx 60-95, \eta_{\mathrm{rad}} \approx 50-110 \mathrm{~lm} / \mathrm{W}\right)$ for stadiums, esplanades and urban lighting.

It can be possible to change the spectrum through the supply mode, on the power balances. Thus, a commercial lamp using "high pressure" sodium, operating under this principle, has been manufactured. It can go from a color temperature of 2,700 K (yellow), corresponding to a good efficiency but to a poor color rendering, to a value of $3,100 \mathrm{~K}$ (white) with a better color rendering but with a lower efficiency.

As expected, because of the high temperatures reached in the high pressure lamps, their energy balance shows thermal losses that represent 25 to $50 \%$ of the electric power injected into the lamp. The reduction of the thermal losses is thus a major target in the research for an improved light efficiency. The thermal losses 
being proportional to the temperature gradient and to the thermal transfer coefficient, both directions must be investigated. However, it must be noted that the material transport phenomena often play an important role and that their control is necessary. The discovery of bulbs that are more thermally resistant could also reduce the temperature gradient while making the evaporation of some less volatile compounds easier. The ceramic metallic halogen lamps (C-MHL) are an example of such a principle (Figure 7.8).

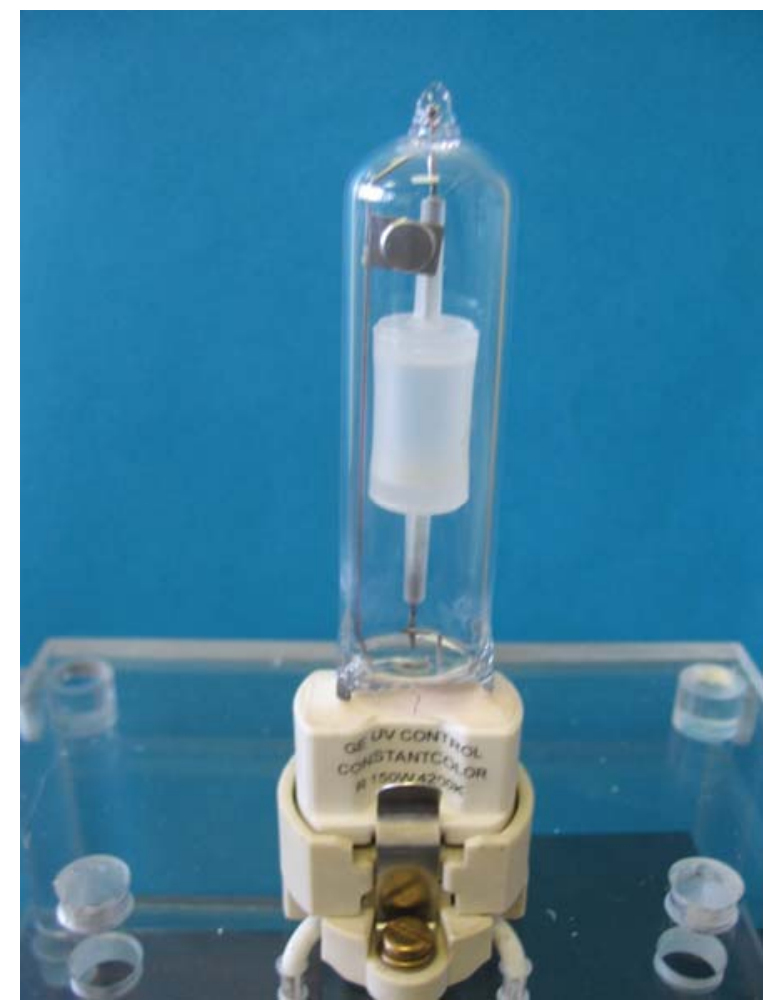

Figure 7.8. Ceramic metallic iodide lamp $(150 \mathrm{~W})$ (source SIP-CPAT)

These lamps generate a good quality white light (CRI in the order of 95) and they have a good efficiency (exceeding $100 \mathrm{~lm} / \mathrm{W}$ ). They have a long lifetime (more than $12,000 \mathrm{~h}$ ) and an excellent chromatic stability. They are compact and are available in many nominal powers, from $20 \mathrm{~W}$ to $400 \mathrm{~W}$. If the high power versions (from 150 watts) are invading the urban lighting market, the low power lamps will soon tackle the decorative and interior lighting market, replacing incandescent lamps.

Finally, in this family the UHPTM (Ultra High Precision) lamp must be mentioned. This lamp, which operates under 200 bars (mercury vapor) in a few cubic millimeters, is devoted to projection video systems. It really is a revolutionary lamp because the mercury plasma is so dense that it is close to the conditions of a liquid. On the other hand, during the operation, the electrodes are so hot that the tungsten fusion temperature is largely exceeded. Since the electrode is liquid during the operation of the lamp, there is thus a "liquid-plasma" interface. The physics 
which govern this particular discharge and its electrode are still not perfectly controlled, although the lamp, which is widely marketed, is operates correctly for more than 1,000 hours.

\subsubsection{2. "Low pressure" discharge lamps}

Fluorescent lamps are the best known lamps in this family. Fluorescent lamps ${ }^{16}$ are technologically mature nowadays. Furthermore, it is the type of discharge lamp that is the most widespread in the world.

It is true that thanks to a better understanding of the physical processes which govern their operation and also because of the important improvement made in the field of materials, fluorescent lamps have been considerably enhanced since they first appeared. Moreover, the discovery of luminophores resistant to $185 \mathrm{~nm}$ ultraviolet bombing, led to a reduction in the diameter of fluorescent lamps from 38 to $24 \mathrm{~mm}$ and then to even further reduced diameters. These successive reductions of diameters have led, thanks to the change in the discharge characteristics, to more efficient lamps and particularly to more efficient lamp-luminary systems. On the other hand, taking into account the phenomena at the electrodes and the interactions between the plasma and its supply has allowed the choice of frequencies and wave shapes. These improvements have favored the generation of light and the modification of its properties. They also have offered to the user the possibility of better control of lighting installations.

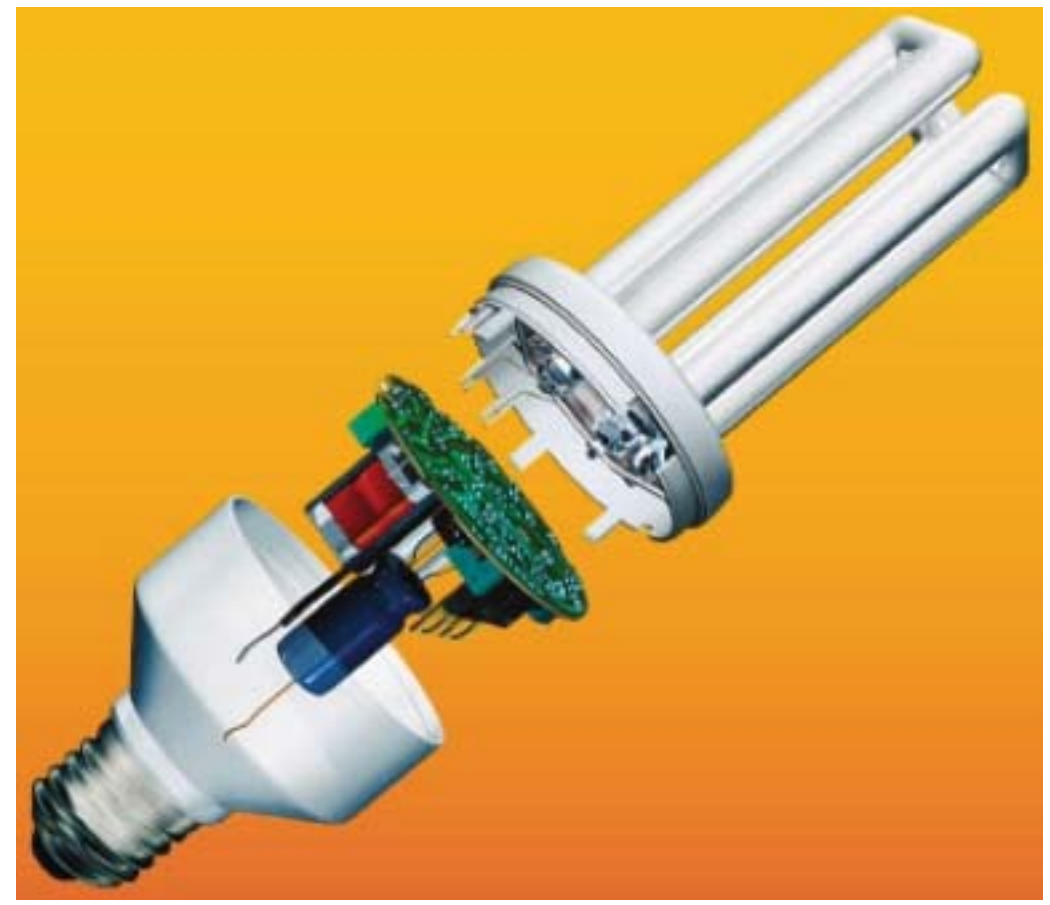

Figure 7.9. Compact fluorescent lamp (CFL) with its integrated electronic ballast (with the permission of Osram $\mathrm{GmbH}$ )

16. Fluorescent lamps are incorrectly called "neon" lights. They do not contain this gas. 
Compact fluorescent lamps ${ }^{17}$ (CFL) have appeared in parallel. The principle of operation is the same as the lineic fluorescent lamps, but the tube is "folded" here many times to guarantee the compactness of the lamp. On the other hand, to make their integration easy in the luminary, "integrated electronic ballast", which is light and compact, has been developed and included in the lamp base. This thus defines two types of compact fluorescent lamps: the lamps with a ballast integrated into the base, which are interchangeable with standard incandescent lamps (Figure 7.9), and lamps without the integrated ballast, which require specially-adapted luminaries (and which include this ballast necessary for the operation of the lamp).
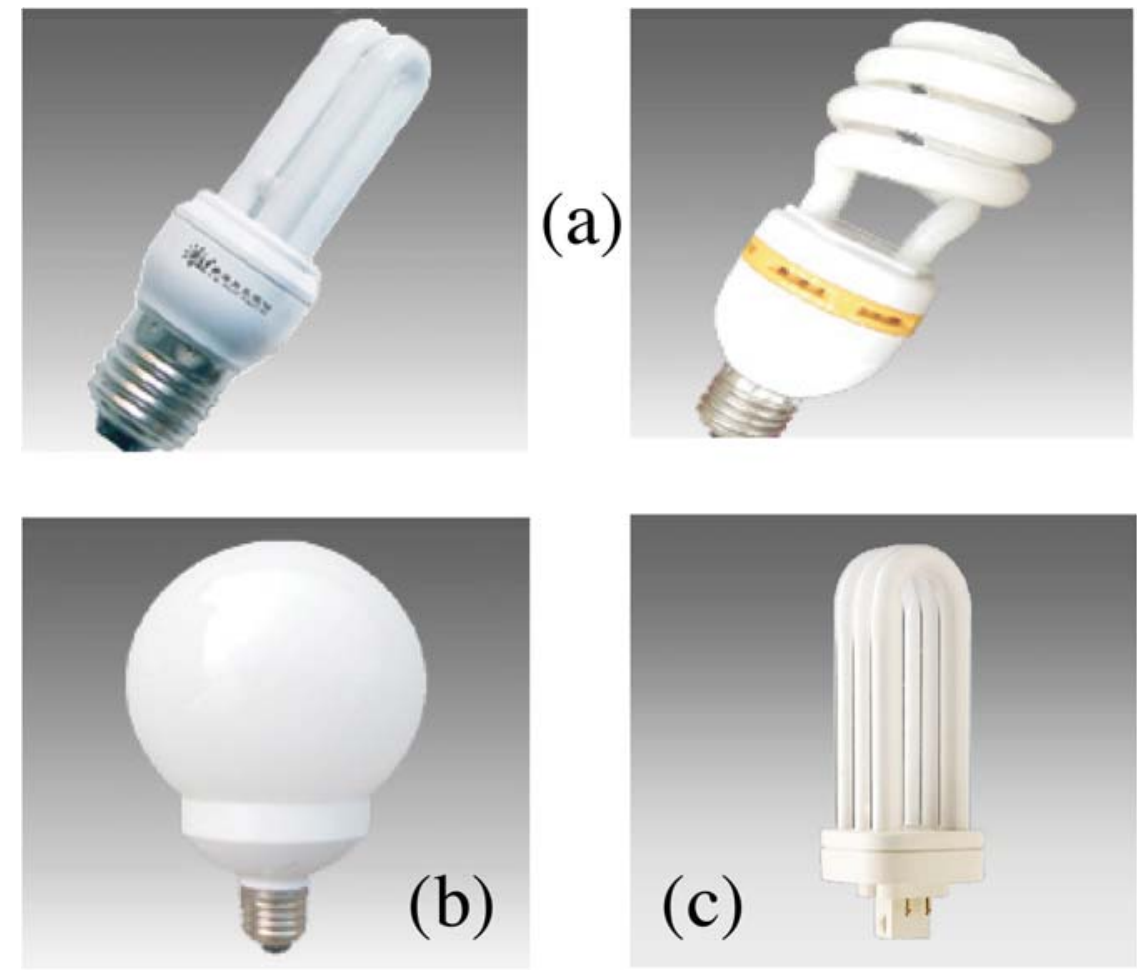

Figure 7.10. Compact fluorescent lamps: (a) with ballast integrated into the base; (b) lookalike and (c) without integrated ballast

CFLs today represent a market of about $8 \%$ in the residential area. The advantages are well known: they present a good efficiency (40 to 80 lumen/W), they are cheap when used under good conditions (use in rooms where lighting is durable), their lifetime is from 6,000 to 12,000 hours (estimation based on a single lighting per day). Let us point out that the significant efficiency range of the CFL (40 to 80 lumen/W) may be explained by many reasons: for the same type of lamp (shape and power) the efficiency strongly depends on the quality of the manufacturing line: the majority of the "made in China" lamps have a lower efficiency. In the same way, this also strongly depends on the quality of the electronic ballast integrated into the base of the lamp. On the other hand, the shape also has an impact of the efficiency, especially for the look-alike lamps (Figure 7.10) because a second spherical

17. The CFLs are commonly known under the name LCL (Low Consumption Lamp). 
envelope must be added to achieve the shape of an incandescent lamp; this of course will also have an influence on the general efficiency of the lamp.

Despite all these improvements, there are still nowadays many scientific challenges in the field of fluorescent lamps:

- How can we avoid 50\% of losses due to the luminophores? The answer probably lies in using luminophores able to generate two visible photons for each incident UV photon. This solution is possible but still expensive and less efficient. Another solution would consist of generating visible light directly, using volatile molecules or other gases. The research into new emissive bodies meets the second challenge described in the case of high pressure lamps.

- How can we avoid the use of mercury? Mercury, which is liquid at ambient temperatures and easily vaporizable, also has interesting atomic properties and seems to be unavoidable. However, mercury generates, especially at low pressures, a hard ultraviolet radiation and it is considered a highly toxic element. Many possibilities may be considered for its replacement:

- xenon generates a "hard" ultraviolet radiation at $147 \mathrm{~nm}$ which destroys the current luminophores and the generation efficiency is low (2.5 times lower than that for mercury). However, the xenon low pressure discharge generates light instantaneously;

- neon, one of the first gases used in the discharge field, generates red light at low pressures $(100 \mathrm{~Pa})$. By increasing the pressure to more than $104 \mathrm{~Pa}$ and with adapted luminophores, white light can be generated but with a low efficiency (20 $\operatorname{lm} / \mathrm{W})$

- molecular emitters. Unfortunately, the presence of metallic electrodes strongly reduces the choice of usable gases. Some tests showed that hydroxyl (OH-) could play the role of the emitter gas but its use is very complex.

- How can we miniaturize fluorescent lamps? Although CFLs are more "compact" than linear fluorescent lamps, the efforts to miniaturize the source still continue.

- How can we control the color? Color control of the low pressure tubes is very important for applications such as signaling and display advertising. It is possible to control the discharge color with a convenient choice of the gaseous mixture (with or without mercury) and the associated luminophores. Another easier method consists of controlling the selective excitation of the emissive bodies by changing the characteristics of the discharge electric supply (wave shape, duty cycle, frequency). Thus, a Hg-Ne lamp may switch from a blue color $(\mathrm{Hg})$ with sinusoidal excitation, to red $(\mathrm{Ne})$ when the lamp is excited in pulse mode. 
- How can we reduce the starting time? Let us note that this starting time idea is difficult; indeed, we are faced with important discrepancies according to the measurement mode. The available data show a delay of about 10 min whereas measurements performed by others give $3 \mathrm{~min}$ instead. It is not possible to conclude, but we must say here that this problem of starting time is important for the CFL user who, used to incandescent lamps, desires instantaneous lighting. The development of robust electronic ballast could partially solve this problem.

\subsection{Discharge lamps without electrodes or molecular emitters}

Almost all the discharge lamps used for lighting are equipped with electrodes to inject electric energy into the discharge and to guarantee a transition from the metal conduction to the gaseous conduction. Although the current electrode technology is better controlled, the presence of these metallic elements in the plasma seriously limits the lifetime of the lamp and also reduces the choice of the emitter gases. The elimination of the electrodes solves many problems and also simplifies the manufacture of the lamp. It is indeed possible to inject the electric power in the discharge by coupling, in an inductive or capacity way, the plasma with the supply circuit. The use of microwaves is also an alternative. Today, three different technologies exist: induction fluorescent lamps, dielectric barrier lamps using excimer radiation and microwave lamps.

The best known lamps without electrodes are "induction" lamps. The operation principle is similar to that of CFL. Today, there are products in this family on the market, for example, the $\mathrm{QL}^{\mathrm{TM}}$ (Philips), the Genura ${ }^{\mathrm{TM}}(\mathrm{GE})$ and the Icetron $^{\mathrm{TM}}$ (Osram). The target applications are mainly devoted to ambient public lighting, since the price is still very high and despite the very long lifetime of these lamps, the depreciation is very long.

Dielectric barrier lamps use the emission of excimer molecules. These molecules, which do not exist in the normal conditions (the fundamental level is anti-bounding), may exist for very short times at a radiative excited state. Today, we can control the production of these unstable molecules very well in an electric discharge at atmospheric pressure far from local thermodynamic equilibrium conditions.

An important advantage of the excimer lamps is that any geometric shape of the tube is possible, due to the absence of electrodes. Furthermore, the lifetime, as in the case of induction lamps, is thus very long ${ }^{18}$. Moreover, a large choice of wavelengths is possible because there is no limitation in the choice of emissive body for the electrodes. For instance, we can mention a Xe-SF $\mathrm{S}_{6}$ lamp for the generation of

18. Lifetimes from $60,000 \mathrm{~h}$ to more than $100,000 \mathrm{~h}$ have been announced. As a comparison, an electrode lamp rarely exceeds $20,000 \mathrm{~h}$ and an incandescent lamp 2,000 h. 
a quasi-monochromatic radiation of around $370 \mathrm{~nm}$ produced by $\mathrm{Xe} * \mathrm{~F}$. We can also mention another lamp with $\mathrm{Xe}-\mathrm{Cl}_{2}$ which generates a $308 \mathrm{~nm}$ radiation because of the $\mathrm{Xe} * \mathrm{~F}$. Regardless of these advantages, over the last decade this technology could only be used for industrial applications (photo polymerization, surface treatment, depollution, etc.).

However, attempts in using excimer lamps for general lighting and signaling have been made for many years. Osram has thus put onto the market a flat lamp called Planon ${ }^{\mathrm{TM}}$ (Figure 7.11). This lamp uses xenon as an active gas (up to a pressure of a few hundred mbars) to generate a radiation at $147 \mathrm{~nm}$ coming from the excimer molecule $\mathrm{Xe}_{2}{ }^{*}$. This radiation is then transformed into visible light by means of luminophores, as in an ordinary fluorescent lamp. The Planon ${ }^{\mathrm{TM}}$ lamp is a very interesting concept, but in the first version its efficiency was $27 \mathrm{~lm} / \mathrm{W}$. It was too weak a value to compete against a fluorescent lamp. This flat lamp may be used for general lighting and for signaling. Indeed, it is possible to combine many Planon $^{\mathrm{TM}}$ lamps to have a large display panel visible from a long distance.

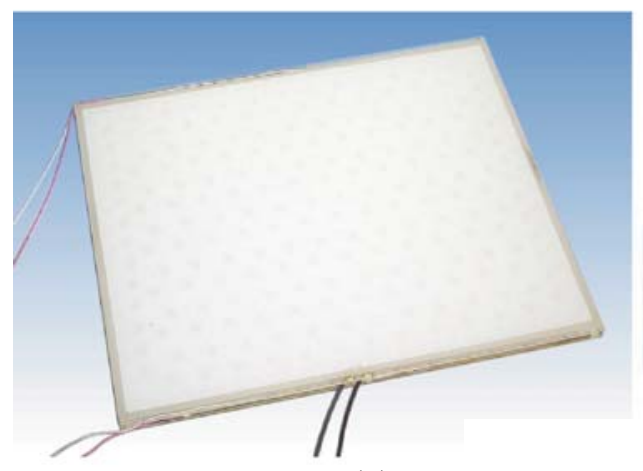

(a)

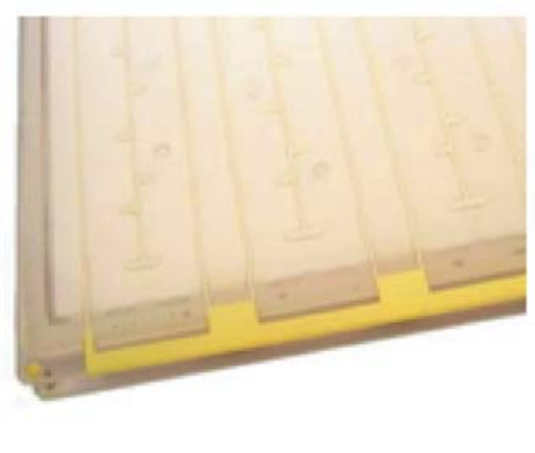

(b)

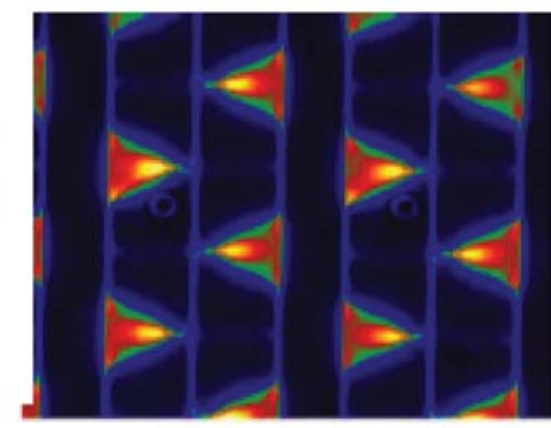

(c)

Figure 7.11. a) The Planon ${ }^{\mathrm{TM}}$ lamp from Osram; $b$ ) its "planar" electrode structure and c) the "conical" micro discharges which generate the excimer radiation

Another attempt at making an electrodeless lamp devoted to general lighting consists of using molecular emissions (spectral bands) and of course, it also consists of supplying energy to the discharge by means of microwave sources. This concept allows the generation of white visible light without a luminophore. The first attempt in this field was the sulfur lamp. Fusion (USA) developed this for public and monument lighting. Microwaves supply this lamp and its efficiency is about $100 \mathrm{~lm} / \mathrm{W}$. Figure 7.12 shows this lamp and its main characteristics. 

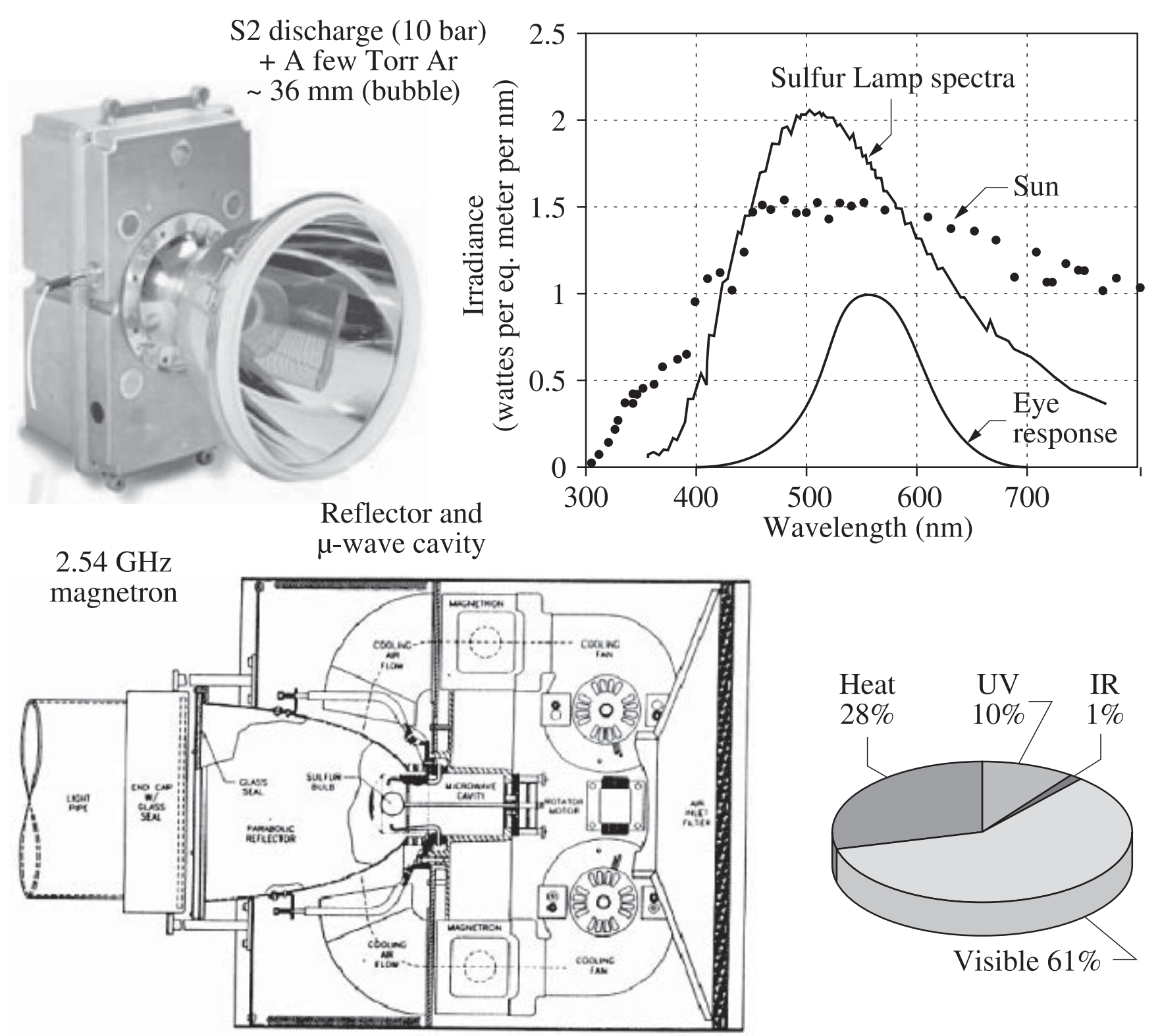

Figure 7.12. The sulfur lamp, its spectrum and its energy balance

Unfortunately, this lamp generates a light of relatively poor quality in terms of colors and its application is, at the moment, very limited. On the other hand, the system requires permanent cooling so the spherical bulb is rapidly rotating in the system. However, despite its poor commercial success due to these gaps, this lamp may be considered a revolution in the field of light sources. We are today convinced that the use of molecular emissions, combined with the electrodeless lamp technology, may result, within a few years, in the development of new products, that are more efficient and generate a light of better quality and in large quantity, with a long lifetime. Will this be the light source of the future?

\subsubsection{Electroluminescent diodes}

There is also a revolution in the field of light sources. In 1907, H. J. Round announced the first light emission of a semiconductor [ROU 07]. With no clear 
explanation, this discovery was rapidly forgotten. We had to wait until 1962 before Nick Holonyak and S.F. Bevacqua from General Electric sign the "official birth certificate" of the red electroluminescent diode [HO 01]. Since then, events have accelerated. In 1968, the first electroluminescent diode (or LED, for Light-Emitting Diode) on the market generated a red light of just $0.001 \mathrm{~lm}$. Today, white LED lamps exist on the market and generate more than 1,000 lumens. This quick historical reminder shows that even if large difficulties remain and still make a rapid and large lighting market penetration impossible, it is realistic to think that LEDs have a future in this area.

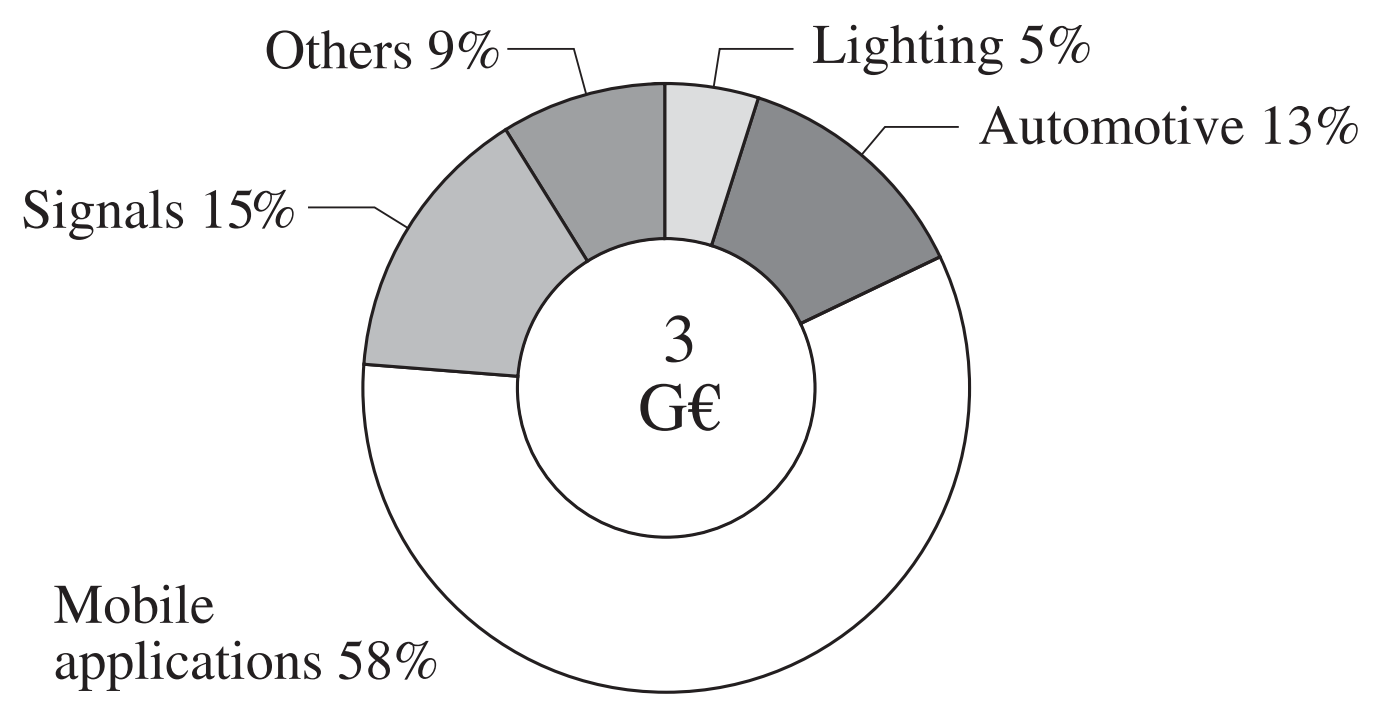

Figure 7.13. LED market in 2004

Today, according to Russ Arensman [ARE 05], the world LED market is valued at around 3 billion euros and its annual growth is $14 \%$. If this rate is confirmed and maintained during the five coming years, this area would represent in 2009 about 6 billion euros and would exceed 10 billion in the following decade. However, today, the penetration of LEDs in the field of general lighting remains about 5\% (Figure 7.13). Will this portion increase in the next few years? Despite the general optimism, supported by the spectacular scientific progress loudly announced by the manufacturers, the question today has no clear answer.

The simplified operating principle of an LED is as follows: the basic element of an electroluminescent diode is a semiconductor with two regions of different conductivity ( $p$ - and n-type) and a region of radiative recombination of the " $n$ " (electron) and "p" (hole) carriers. Under the effect of a potential difference applied between the two layers, electrons penetrate the n-type layer. This is equivalent to an injection of holes in the p-type layer. At the interface of both zones, electrons and holes recombine and give a photon thereby generating light (Figure 7.14). 


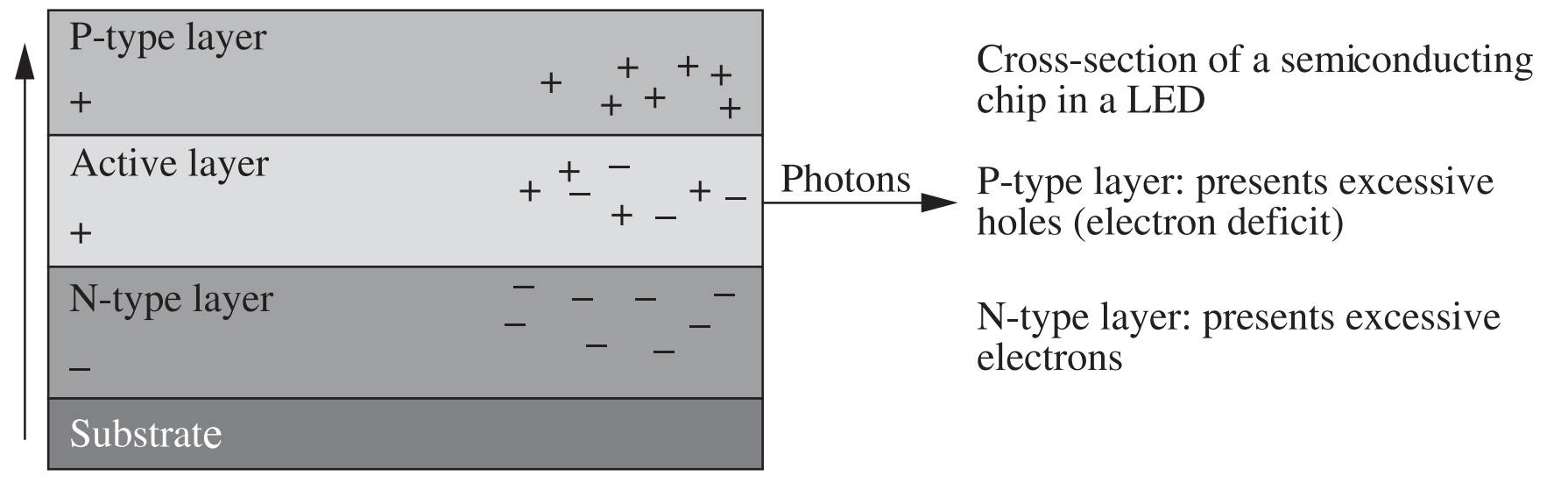

Figure 7.14. Simplified operating principle of LEDs

At the equilibrium state, the majority carriers of each region diffuse to the other zone: the electrons of the " $n$ " region tend to diffuse to the "p" region, holes move in the opposite direction. These spontaneous motions disturb the local electric neutrality of the system and are at the origin of a "space charge" field, which, in turn, opposes these motions and the system balances itself. Consequently, the number of minority carriers in each region (electrons in the $\mathrm{p}$ region and holes in the $\mathrm{n}$ region) stays very weak and the radiative recombination probability is almost zero. Now, when applying a direct polarization voltage $\mathrm{V}$ to the junction, the potential barrier decreases by a value equal to $\mathrm{eV}$. Consequently, the diffusion current of the majority carriers at each side of the barrier to the opposite region increase by a factor proportional to $\exp \left(e V / k_{B} T\right)$, where $\mathrm{T}$ is the junction temperature and $k_{B}$ is the Boltzmann constant. This diffusion current increase unbalances the system and leads to a population growth of the minority carriers in each region. If the direct polarization voltage is high enough, the radiative recombination probability is no longer negligible and the junction generates photons. The principle discussed above corresponds to a so-called "homo-junction" electroluminescent diode. The classical LEDs still use this structure today. However, the new high intensity diodes use many complex junctions, called "hetero-junctions". They operate on the space variation of the semiconductor composition. These structures are combinations of different chemical composition semiconductors also with different energy gaps. Today, we use simple $(\mathrm{SH})$ or double $(\mathrm{DH})$ hetero-structures.

The LEDs carry many hopes for lighting. In a white paper ordered by the US Senate, R. Haitz et al. have developed two scenarios [HAI 02]: the first, "evolutionary" scenario only foresees a white diode of $50 \mathrm{~lm} / \mathrm{W}$ for 2010 , whereas, the second, "revolutionary" scenario targets a $250 \mathrm{~lm} / \mathrm{W}$ system from now to 2025 . According to the first scenario, the $150 \mathrm{~lm} / \mathrm{W}$ seems to be a realistic objective, which can be reached without considerable effort. In this context, LEDS may very well replace from now to 202520 to $30 \%$ of the incandescent and halogen lamps. This would result in an energy saving of about $400 \mathrm{TWh} /$ year (corresponding to a 
generation capability reduction of $50 \mathrm{GW}$ ). In the second scenario, a $200 \mathrm{~lm} / \mathrm{W}$ goal clearly requires a considerable effort. In that case, LEDs would be able to replace the fluorescent lamps and could represent more than $50 \%$ of the light source market share from now to 2025-2030. The energy savings envisaged would then be of about 1,000 $\mathrm{TWh} /$ year (corresponding to a generation capacity reduction of $120 \mathrm{GW})$.

Furthermore, LEDs offer major advantages:

- a strong development potential of their efficiency (in theory $100 \%$ of electricity into light transformation);

- a long lifetime: the foreseen objective, on which there is consensus, is to make a diode with a lifetime from 40,000 to 50,000 hours from now to 2025 (rather than the 100,000 hours announced a few years ago);

- high quality saturated colors, providing a good light perception by the user;

- an easy supply, a low energy demand;

- high brightness.

However, there are also well known drawbacks. The aspects that are not currently solved are as follows:

- the above scheme clearly shows that LEDs can only generate light "nibs": light is at the same time directional and monochromatic. Obviously, this is a huge drawback for general lighting (where a diffuse and non-blinding light is required). To solve this problem, heavy optics is necessary, which is expensive and damages the light efficiency. Because of these characteristics, the present applications are limited to spots and additional lighting;

- aging is erratic; the color "changes with time". The flux generated by white LEDs decreases quite linearly from the first hour of operation. Flux drop measurements have been made on a $1 \mathrm{~W}$ white diode. They show that the flux is reduced by half in 6,000 hours (this is data from 2000, we do much better today...). Advances in this field are thus also necessary for electroluminescent diodes to dominate the market one day;

- there are problems for mass production reproducibility for white LEDs only (non-identical color temperature);

- LEDs are limited to low powers: currently less than $5 \mathrm{~W}$. It is mainly a thermal management problem of the junction since the heat generated by the diode operation changes its performances;

- the energy consumption is low. This contributes to give the diode an "environmental" image, but the production technique is, itself, less "green" 
(semiconductor industry). This point must be compared to the present-day lamp industry, which is very clean (few toxic wastes generated).

These problems are a snapshot, made at mid-2006; they might make us smile in the next few years, but today, nobody can say at what speed they will be solved.

One of the major problems with LEDs is because the light emitted is monochromatic. For this reason, one of the basic problems for the research consists of progressing towards a "white LED" with more than $100 \mathrm{~lm} / \mathrm{W}$ of efficiency. Today, the commercial junctions only offer $25 \mathrm{~lm} / \mathrm{W}$ of efficiency.

Three methods exist today to make an electroluminescent diode that generates white light:

- combining one diode emitting a short wavelength $\lambda_{1}$ with a luminophore (phosphorus) emitting a complementary wavelength $\lambda_{2}$ (long);

- using a diode emitting in the near ultraviolet range, coupled with one or more luminophores;

- using (at least) three diodes emitting visible wavelengths which combine to give a white light.

Each of these methods has advantages and drawbacks.

The first method is based on the fact that two photons of complementary wavelengths ( $\lambda_{1}$ "short" and $\lambda_{2}$ "long") simultaneously reaching the human eye cause a white light feeling. The main idea is then to use a short wavelength diode covered with phosphorus, which absorbs some short photons, and transforms them into longer wavelengths. In principle, an infinity of combinations is possible. Practically, some manufacturers (Nishia, CREE, Lumileds, etc.) have a mass production of high intensity white diodes (up to $5 \mathrm{~W}$ today) using a blue diode (InGaN) combined with a yellow phosphor (YAG-Ce). In the short run, this technology will probably dominate the white diode market. However, it presents two drawbacks:

- The diode has a halo effect, which may be disturbing for some applications. This is due to the directional light generated by the white diode, whereas phosphorus has a Lambertian behavior (diffuse emission).

- The yellow phosphorus does not easily absorb the blue photons. This problem is raised because the present-day yellow phosphorus has a very low absorption in the blue because of the rare earths used as doping elements. The solution to the problem seems complex and requires a lot of research. 
To reach an efficiency of $200 \mathrm{~lm} / \mathrm{W}$ for the generation of white light in this technology associated with existing phosphorus would require a diode with a total conversion efficiency of $60 \%$. Today, the best-known efficiency is $45 \%$ at a wavelength of $610 \mathrm{~nm}$.

The second method consists of using a short wavelength diode (in the near ultraviolet or in the violet range) coupled with one (or many) phosphor(s) that transform the UV light into visible light. This technique is used today in fluorescent lamps. It presents the advantage of generating a good quality white light (good color rendering index). To use this technology to obtain $200 \mathrm{~lm} / \mathrm{W}$, as previously discussed, requires a UV diode with a total efficiency of $70 \%$. Diodes generating $400 \mathrm{~nm}$ photons (violet) exist but the efficiency is almost 21\%. To increase this efficiency up to $60-70 \%$ is a fantastic challenge but probably unrealistic in the present day state of art. However, we can note today a huge research activity in this field. The development of efficient UV diodes with a long lifetime and sufficient power represents an important challenge especially for lighting but, also, for other equipment using UV radiation in some applications (dermatology, surface treatment, decontamination, etc.). If this technology appears to be efficient, and if in the future, research on the luminophores brings onto the market good quality and reliable white phosphorus, this technique may then become the leading technology for white light generated by LEDs.

Finally, the third method consists of using three electroluminescent diodes, one for each main color (red, green and blue). The synthesis of three colors leads to the generation of white light, the color and temperature color of which depend on the proportion of each of the three components. Since the dimensions of a diode are small, we can think about the generation of "composite" white lights to which the addition of a diffuser would considerably improve the homogenity of the source. This method has many advantages: avoiding the use of luminophores, allowing a good control of the light quality (color rendering index, source color temperature). However, this technology has a major drawback: every single diode, out of the many dozen LEDs that make the composite source (even several hundred in some cases), must be controlled "individually". We also have to take into account the fact that the diodes of each elementary color require a different voltage supply. A direct consequence of these drawbacks is the price increase of the light source. Finally compared to a standard lamp of the same light flux, the "surface" of the composite source is considerable. To use this solution to reach the $200 \mathrm{~lm} / \mathrm{W}$ target requires the use of electroluminescent diodes with $50 \%$ efficiency for each color...

Today, electroluminescent diodes, for the previously-mentioned reasons, have difficulties in proving their efficiency in the general lighting field. However, they have proven their efficiency in the field of signaling and they are penetrating the specialized lighting market. Figure 7.15 outlines the LED application fields 
according to color and flux [ZIS 04]. Signaling applications often require low light flux and a monochromatic light. For light, we need white light and important light flux.

On the other hand, if, in the 1970s, a single LED was used as an "indicator" (on/off, breakdown, level, etc.) in the control panel of electric appliances, more complex signaling systems (for instance traffic lights) use several dozen LEDs for a single function. The development of high intensity diodes will probably lead to systems dedicated to lighting that will operate with a limited number of diodes.

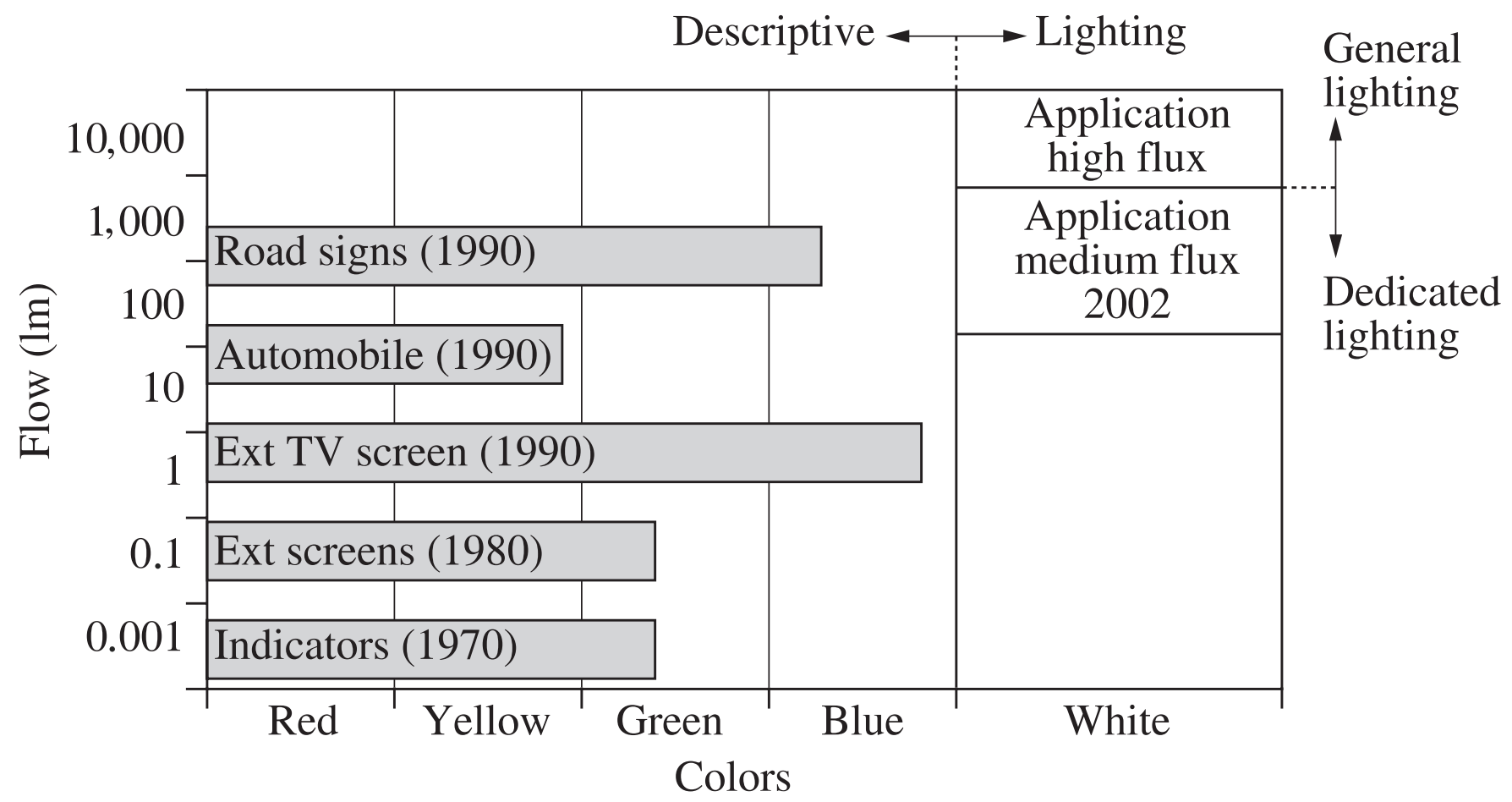

Figure 7.15. Application field of electroluminescent diodes according to their radiated flux and their color

The perspectives of research and development in the field of LEDs are important; the following list indicates some that are considered to be relevant [OID 02]:

- Fundamental research into materials and light generation: first of all a better understanding of the light generation mechanisms by semiconductors is necessary. This is why we must develop new diagnosis techniques adapted to LEDs and more sophisticated mathematical models than those available today. For the time being, the understanding of problems due to p-type doping faults and the addition of high indium and aluminum concentrations in the green diodes InGaN and AIGalnN, lead to the production of more efficient green diodes. As with the study of the carrier containment in phosphide-based LEDs, this seems to be the key for the achievement of more efficient red diodes. 
- Substrate materials: today, for the development of GaN family diodes, which seem to be among the most promising, sapphire substrates, $\mathrm{SiC}$ or $\mathrm{GaN}$ must be used. Each of these three materials shows advantages and drawbacks. However, we are not able to produce large faultless surfaces with these materials. The solution to this problem must be considered as a priority in this field. On the other hand, it would be advisable to be able to reduce the substrate production cost to less than $70 € / \mathrm{cm}^{2}$ (for UV, green and blue diodes).

- Reactor technology for manufacturing diodes by epitaxy: the reactors used for mass production of the $\mathrm{GaN}$ family electroluminescent diodes are just machines developed for manufacturing GaAs diodes. If their reliability is good for the production of GaAs diodes, it is very bad for making modern GaN diodes. Thus, the diodes, mass-produced by these machines, quite systematically show efficiencies 1.5-2 times lower than those observed on the prototypes. On the other hand, in the same series produced by a machine, important characteristic dispersions may be noted. The ridiculous example is the manual selection, according to the "color", made at the end of the high intensity white diode production line... To go further in this field, we have to know the process chemistry and the nitride growth mechanism better in order to optimize the reactors.

- Luminophores: the problems of low blue light absorption by yellow phosphorus have already been mentioned. At first, luminophores able to absorb and efficiently convert photons with wavelengths between 370 and $470 \mathrm{~nm}$ must be developed, then it will be necessary to study other possible combinations of complementary colors and develop adequate phosphorus. On the other hand, as for fluorescent lamps, the development of "quantum-splitting phosphors"19 will be a decisive step for LEDs.

- Light extraction and packaging: the improvements of the optical characteristics of transparent substrates and contacts, of the reflecting layers, etc., are important research directions for the near future. To improve the junction geometry in order to increase the light extraction efficiency, or even to look after complex structures such as photonic crystals are longer-term challenges. Finally, it must be recalled that the junction is only a small part of the diode and that the packaging ${ }^{20}$ plays an essential role in its efficiency and reliability.

19. "Quantum-splitting phosphors" are a technology which makes it possible to obtain, for an initial UV photon with an energy E, two or three visible photons of energy E1, E2, E3 $(\mathrm{E}>\mathrm{E} 1+\mathrm{E} 2+\mathrm{E} 3)$. The ideal case, but one which has still not been reached to our knowledge, consists of using a blue, green and red photon to make white light. These phosphoresces are very expensive and need to be recycled at the end of the lamp lifetime. This technology will mainly be of benefit to fluorescent lamps with or without mercury and to LEDs radiating in the ultraviolet range.

20. "Packaging" is a term dedicated to the LED industry that designates the integration of a "semiconductor junction" in an LED (epoxy dome, phosphorus, electric connections, thermal radiators, etc.). 
- Technological challenges must be envisaged in this field. For instance, for a high intensity diode, it would take a transparent material that is easy to machine with a refraction index greater than 1.6 and a transmittance of $80 \%$ from 440 to $650 \mathrm{~nm}$ able to stop completely short photons $(\lambda<440 \mathrm{~nm})$. This material must conserve its characteristics for at least 50,000 hours while being at a temperature of $150^{\circ} \mathrm{C}$. Finally, the water concentration in this material must remain at about a few ppm and its mechanical characteristics must be compatible with the envisaged application.

- Luminaries and electronics: for the LEDs penetrating the lighting market, specific luminaries must be developed that take into account the strong light directivity, the small light source dimensions and especially its sensitivity to temperature, humidity and any other corroding factor encountered in its environment. Finally, because the generation of an enough light for general lighting requires a significant number of LEDs, a sophisticated electronic control is necessary. Let us note here that an LED color is very sensitive to both voltage and current supply. A small variation of one or the other of these quantities will provoke a significant color shift. Moreover, the behavior of every diode changes with time (flux is reduced, color shifts) more or les slowly, but because of lacks at the production level (see above), this variation is different from one diode to the next. They must be controlled individually.

These objectives, clearly announced by researchers for the 15 coming years, are ambitious stakes. Are they realistic? To answer this question by "yes" or "no" would be a speculation on the shape of a puzzle without the cornerstones!

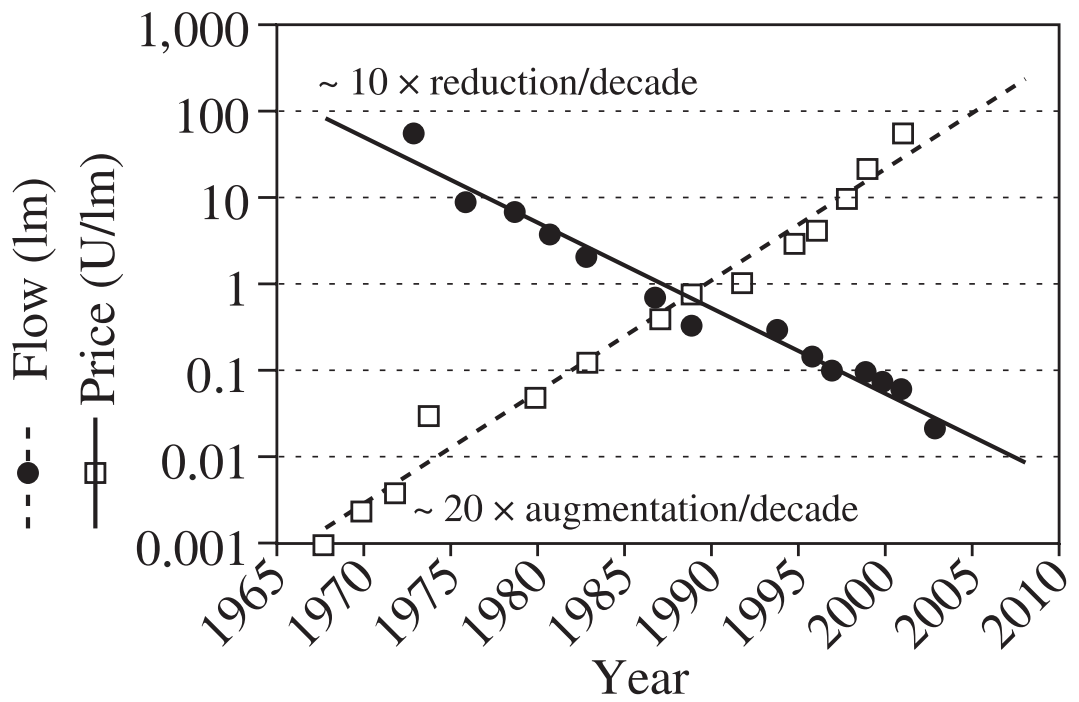

Figure 7.16. Evolution of the flux light generated by LEDs and of their cost

A key argument, often used by LED "supporters", is the rapid evolution of the light quantity (flux) generated by a diode. Indeed, as shown in Figure 7.16, the flux per diode is multiplied by 20 every 10 years. At the same time, the price decreases 
by a factor of 10 during the same period. Today, the researchers call these tendencies the "Craford laws".

These arguments are very encouraging. However, we must bear in mind that the quantities in Figure 7.16 concern not only white LEDs, but also the diodes of each color. On the other hand, nobody can guarantee the extrapolation of these curves until 2020-2030. Their evolution may remain steady, vanish or accelerate even more quickly.

\subsection{Organic electroluminescent diodes (O-LED)}

Organic electroluminescent diodes (O-LED) are the organic version of LEDs. This technology, patented in 1987 by the Kodak Company, was initially devoted to signaling applications and its first commercial application appeared around 1997. Since then, O-LEDs have evolved considerably, to obtain modules generating white light with an efficiency of $32 \mathrm{~lm} / \mathrm{W}$ and Universal Display Corporation announced $102 \mathrm{~lm} / \mathrm{W}$ in July 2008. In this context, and if the lifetime problems are solved, OLEDs will be a serious competitor to standard LEDs, because contrary to LEDs, OLEDs have an important and necessary "extension" to general light applications (Figure 7.17).
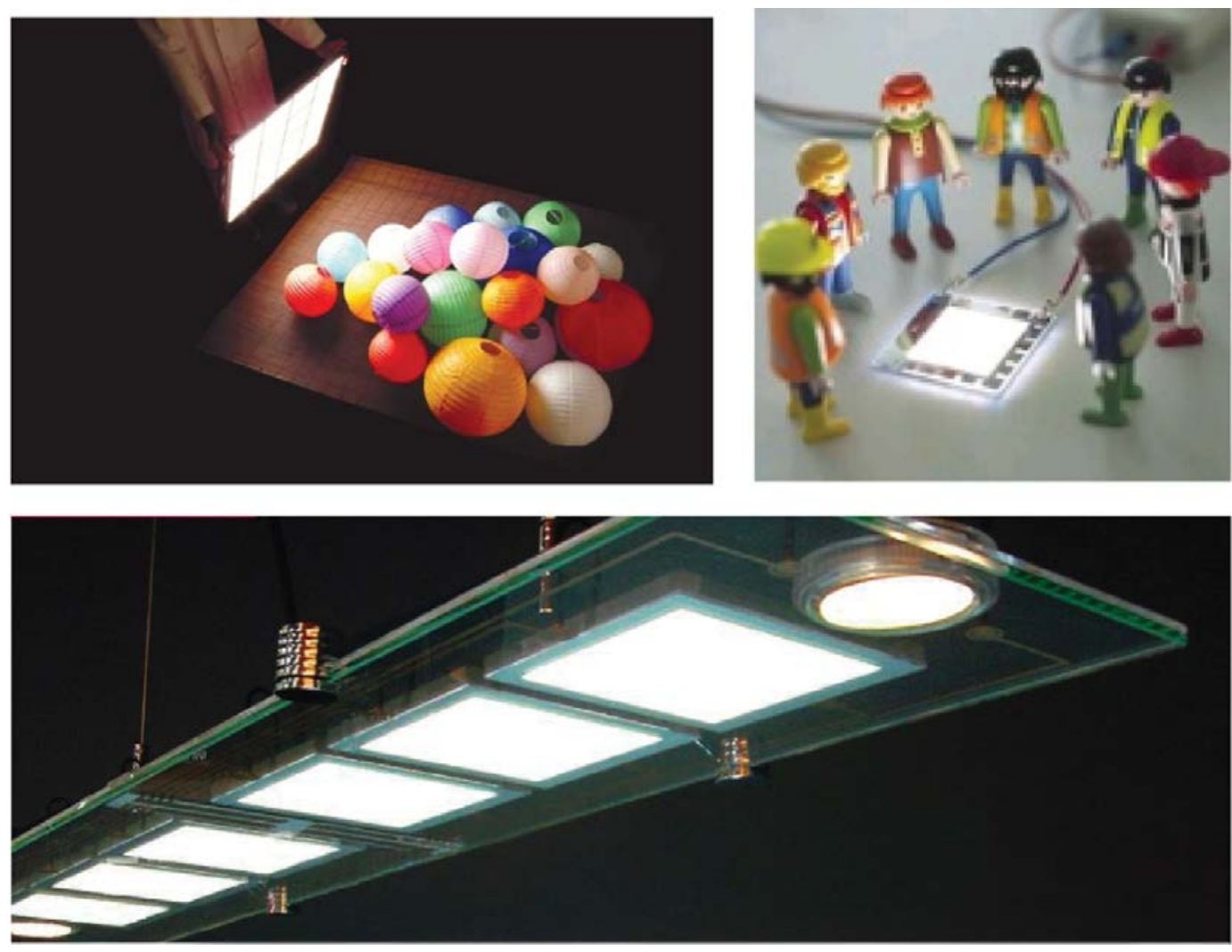

Figure 7.17. Some O-LEDs prototype modules (top right the Novaled-Philips with a light efficiency of $32 \mathrm{~lm} / \mathrm{W}$; top left a prototype General Electric; at the bottom, a prototype luminary) 
Indeed, in an O-LED module, each diode, the thickness of which does not exceed one millimeter, contains three layers of an organic semiconductor (plastic film) surrounded by transparent electrodes (at least one of the two if we want light to "come out"). Every "light pixel" is made of three electroluminescent diodes placed side-by-side (one red, one green and one blue).

Here are some other advantages that O-LEDs seem to have in their favor:

- possible implementation on large surfaces (light signaling panel), which assumes a possibly very large lighting application and the associated scale savings;

- important potential efficiency: $102 \mathrm{~lm} / \mathrm{W}$ (at the prototype stage 2008);

- simple supply (rectified grid, $10 \mathrm{~V}$ ); possible light gradation, theoretically without problem;

- non-directional color or white light (large surface Lambertian emitters);

- light and flexible products (plastic).

The future will prove if this emerging technology will take market shares in the lighting field.

\subsection{Energy savings in the lighting field: some typical case studies}

Now, since we have seen the different technologies and the challenges of the light sources that dominate (or that will dominate) the general lighting field, we will discuss the possible energy savings in some key areas: residential and urban.

\subsubsection{Residential lighting}

The residential lighting area represents $30 \%$ of the total energy bill. In Europe for instance, if we could replace one $75 \mathrm{~W}$ incandescent lamp in our houses with one $15 \mathrm{~W}$ compact fluo lamp generating the same light, we could make huge savings. Each family would save an average of $150 \mathrm{kWh}$ per year and since Europe represents about 150 million families, the yearly savings would represent more than $22 \mathrm{TWh}$ or the equivalent of 7 million tons of oil (TEP). However, the behavior of the "residential" user is quite unpredictable and it is far more difficult to regulate through legislature. The solution would consist of using rather incentive means and especially in informing the population of some technology advantages, that are economical in energy. Thus, today, the penetration rate of energy-saving lamps remains very low in this area. 
In the middle- or long-term, the arrival of lamps, which are marginalized at present, is possible. The price decrease of the metallic iodide lamps and the development of ballasts integrated into the lamps - making them interchangeable with the incandescent lamps - may let us imagine a breakthrough at the domestic level. For the same reason, regarding the electrodeless lamps, their cost reduction combined with a very long lifetime, make them competitive. On the other hand, it is not unthinkable that when LEDs come onto the residential lighting market, the latter will be always divided between incandescent lamps (GLS and halogens) and CFLs. The question of long-term distribution will then be raised between incandescent lamps, CFLs and LEDs. To try to come up with an answer, we imagined three scenarios; depending on the user behavior (we already showed that this point has a fundamental impact on the development of the different products):

- the "standard" scenario consists of extrapolating the future on the basis of what is known currently and without envisaging significant changes in behaviors;

- the "consumerist" scenario is the "pessimistic" option in which the recognition of the environmental aspects (and the energy savings) and of the advantages of "clean technologies" by the consumer, is the most limited;

- on the contrary, the "green" scenario represents an evolutionary model in which all these aspects (environmental impact, energy savings, "clean" energies, etc.) are massively developed.

This projection was made for the European Commission, in the framework of the EnERLIn ${ }^{21}$ project. The analysis was based on the compilation of a significant number of disparate investigations on this subject. They are thus "averages" that are validated intuitively and by personal experience. The results of this projection, from now to the outlook in 2030, in the residential area, are described in Table 7.3.

\begin{tabular}{|c|c|c|c|c|}
\hline Lamp types & $\begin{array}{c}\text { Present } \\
\text { distribution } \\
\text { (percentage) }\end{array}$ & $\begin{array}{c}2030 \text { projection } \\
\text { "consumerist" } \\
\text { scenario }\end{array}$ & $\begin{array}{c}2030 \text { projection } \\
\text { "standard" } \\
\text { scenario }\end{array}$ & $\begin{array}{c}2030 \\
\text { projection } \\
\text { "green" } \\
\text { scenario }\end{array}$ \\
\hline Incandescent & about 90\% & $75 \%$ & $55 \%$ & $15 \%$ \\
\hline CFL & $8 \%$ & $25 \%$ & $45 \%$ & $75 \%$ \\
\hline LED & $0 \%$ & $0 \%$ & $0 \%$ & $10 \%$ \\
\hline
\end{tabular}

Table 7.3. Penetration rate of the different technologies in the residential area

21. EnERLIn: Energy Efficient Residential Lighting Initiative project EIE-05-0176, http://www.enerlin.enea.it. 
The different points to note are the following:

- In two scenarios out of the three, incandescent lamps remain the most popular in 2030 and only the "green" scenario allows a penetration of LEDs in the residential area. For the same reason, only this last scenario allows CFLs to be the most common.

- More globally, which also confirms this projection, the variation after 25 years, is great depending on the scenario that will be achieved (from 15\% to $75 \%$ of CFL penetration). This will raise a comment: if the consumer perception of the usefulness of moving to energy-saving technologies is so important, it becomes very useful to communicate with the general public on this subject. Moreover, this phase may be followed by incentives, to help the advent of the "green" scenario in a concrete way.

- In the "standard" and the "green" cases, we assumed that the consumer considers the amount of light in a residence to be sufficient. In this context, the consumer does not try to increase beyond measure the number of lamps in his house. On the contrary, the "consumerist" scenario assumes that the user wants to increase the amount of light even if this is not necessary.

In this context, we can easily compute the energy impact of each scenario. Table 7.4 gives this calculation.

\begin{tabular}{|c|c|c|c|c|}
\hline & Scenario & Standard & Consumerist & Green \\
\hline$\frac{\pi}{0}$ & $\begin{array}{l}\% \\
\text { Number } \\
\text { Energy (MWh) } \\
\text { Flux (klm) }\end{array}$ & $\begin{array}{c}55 \% \\
15.4 \\
0.5 \\
12.9\end{array}$ & $\begin{array}{c}70 \% \\
26.6 \\
0.8 \\
22.3\end{array}$ & $\begin{array}{c}15 \% \\
4.2 \\
0.1 \\
3.5\end{array}$ \\
\hline 它 & $\begin{array}{l}\% \\
\text { Number } \\
\text { Energy (MWh) } \\
\text { Flux (klm) }\end{array}$ & $\begin{array}{l}45 \% \\
12.6 \\
0.09 \\
11.9\end{array}$ & $\begin{array}{l}30 \% \\
11.4 \\
0.09 \\
10.8\end{array}$ & $\begin{array}{l}75 \% \\
21 \\
0.16 \\
19.8\end{array}$ \\
\hline Aิ & $\begin{array}{l}\% \\
\text { Number } \\
\text { Energy (MWh) } \\
\text { Flux (klm) }\end{array}$ & $\begin{array}{c}0 \% \\
0 \\
0 \\
0\end{array}$ & $\begin{array}{c}0 \% \\
0 \\
0 \\
0\end{array}$ & $\begin{array}{c}10 \% \\
2.8 \\
0.01 \\
1.4\end{array}$ \\
\hline 哥 & $\begin{array}{l}\text { Energy (MWh) } \\
\text { Variation \% } \\
\text { Flux (klm) } \\
\text { Variation \% }\end{array}$ & $\begin{array}{c}0.6 \\
21 \% \\
24.84 \\
13.9 \%\end{array}$ & $\begin{array}{c}0.9 \\
-24 \% \\
33.12 \\
35.4 \%\end{array}$ & $\begin{array}{c}0.3 \\
132 \% \\
24.77 \\
13.6 \%\end{array}$ \\
\hline
\end{tabular}

Table 7.4. 2030 projection of the energy consumption of the residential area for lighting (European Union) 
Today, on average, a residence generally has 28 incandescent lamps (GLS) of about $60 \mathrm{~W}$ and few energy-saving lamps (CFL) of about $15 \mathrm{~W}$. For an operation of $1,000 \mathrm{~h}$ per year, these sources consume $1.4 \mathrm{MWh} /$ capita and generate $21.4 \mathrm{klm}$ of light. In 2030, the efficiencies of the lamps of each type will be about $14 \mathrm{~lm} / \mathrm{W}$ for the GLS, $63 \mathrm{~lm} / \mathrm{W}$ for the CFLs and probably $100 \mathrm{~lm} / \mathrm{W}$ for the LEDs. However, the penetration of each technology cannot be easily envisaged. Table 4.4 gives three possible scenarios: "standard", "consumerist" and "green".

We immediately note that, at the European Union level, according to the "standard scenario", we have an energy saving of $26 \%$ compared to the current situation. The "green" scenario leads to $141 \%$ of savings and at the opposite end, the "consumerist" scenario shows a consumption increase of $21 \%$. From this simple computation, we first conclude that the advent of the "consumerist" scenario must be avoided. Then, we have to act in such a way that the number of economic lamps increases or, at least, stays the same. Unfortunately, the gamble is not paying off! To go further in that direction, it is necessary to continuously promote the technologies that save energy, to create a quality "label" for the best products, to understand the reaction and then to inform the consumer. Finally, it is also necessary to inform and to train the vendors of these products.

\subsubsection{Urban lighting}

Today, the urban lighting area is constantly expanding, and the corresponding energy consumption is growing rapidly. This area, today, makes up about 8-10\% of the total energy bill ${ }^{22}$. It is estimated that an efficiency increase of urban lighting systems may allow, for Europe only, a reduction of 3 to 4 million tons of $\mathrm{CO}_{2}$ waste in the atmosphere; which correspond to a 5\% reduction as planned by the Kyoto agreement. On the other hand, cities are trying to implement lighting systems that guarantee a better quality of life and increased security for their citizens, without forgetting of course to highlight the city itself.

Research is very active in this field. We will present here the results obtained by a European project, which clearly shows the advances that may be achieved in terms of energy savings. Thus, the final objective of the European project NumeLiTe ${ }^{23}$ was to conceive and to produce an innovative urban lighting system combining energy savings and quality of life, and to prove its potential in the city of Albi (Tarn, France). The project, particularly consisted of improving the light source efficiency (which is measured in lumens per consumed electric watt), and improving the color

22. In France, public lighting represents $46 \%$ of a village electricity bill.

23. NumeLiTe ${ }^{\mathrm{TM}}$ : Numerical Light Technology (NNE-01-0282): project achieved in the "Energy program" framework of the European Union. 
rendering, which means having a light which reproduces the colors of the surrounding world well.

The NumeLiTe ${ }^{\mathrm{TM}}$ system is based on arc lamps conceived in the framework of the project. It consists of metallic halogen lamps with a ceramic envelope $(150 \mathrm{~W})$ generating, with an excellent efficiency $(98 \mathrm{~lm} / \mathrm{W})$, a white light of very good quality (IRC 97). Two versions exist of different color temperatures $(3,000 \mathrm{~K}$ and $4,200 \mathrm{~K})$. These lamps contain a mixture of different metals in their iodide form. In operation, the lamp generates a complex spectrum spread over the entire visible domain. The result is a white light of a very good quality. On the other hand, the ceramic envelope, combined with the overall design of the lamp (geometry, electrodes, etc.), guarantees excellent color stability and a long lifetime (estimated at more than $12,000 \mathrm{~h}$ ). They work vertically as well as horizontally. The steady-state rising time is shorter than in a sodium lamp of equivalent power. The nominal voltage remains stable $(+/-5 \%)$ during almost all their lifetime, whereas for most of the high-pressure sodium lamps this same voltage increases with the age of the lamp. These lamps are enclosed in luminaries, the reflectors of which are specially designed to better distribute the light on the road and to avoid the problems of light pollution. New electronic ballasts that allow the light gradation supply the lamps. Today, these ballasts allow the gradation in seven levels, but a continuous gradation will of course be possible in the future.

The lamps of the NumeLiTe project are specially conceived to support this gradation with no reduction in their performances or lifetime. Each light point can be controlled remotely (carrier current link or hertz connection in radiofrequencies) by a dedicated central station installed in the Albi city hall. This allows quality control of the light at all times. It also allows the scheduling of the system operation. Finally, the radiofrequencies used for programming the system offer many additional possibilities for the city (bus location, or public warnings, remote meter readings, etc.). We are thus moving towards an intelligent system for the user.

On the other hand, when the power is reduced, the spectrum radiated by the metallic iodide lamp is voluntarily shifted towards the smallest wavelengths (blue). This is done to take into account the peculiarities of the human eye, which is sensitive at night to wavelengths shifted to blue, in order to increase the energy gains without notably damaging comfort and uniformity. Figure 7.18 shows our visual system response in two extreme cases: the photopic vision and scotopic vision. 


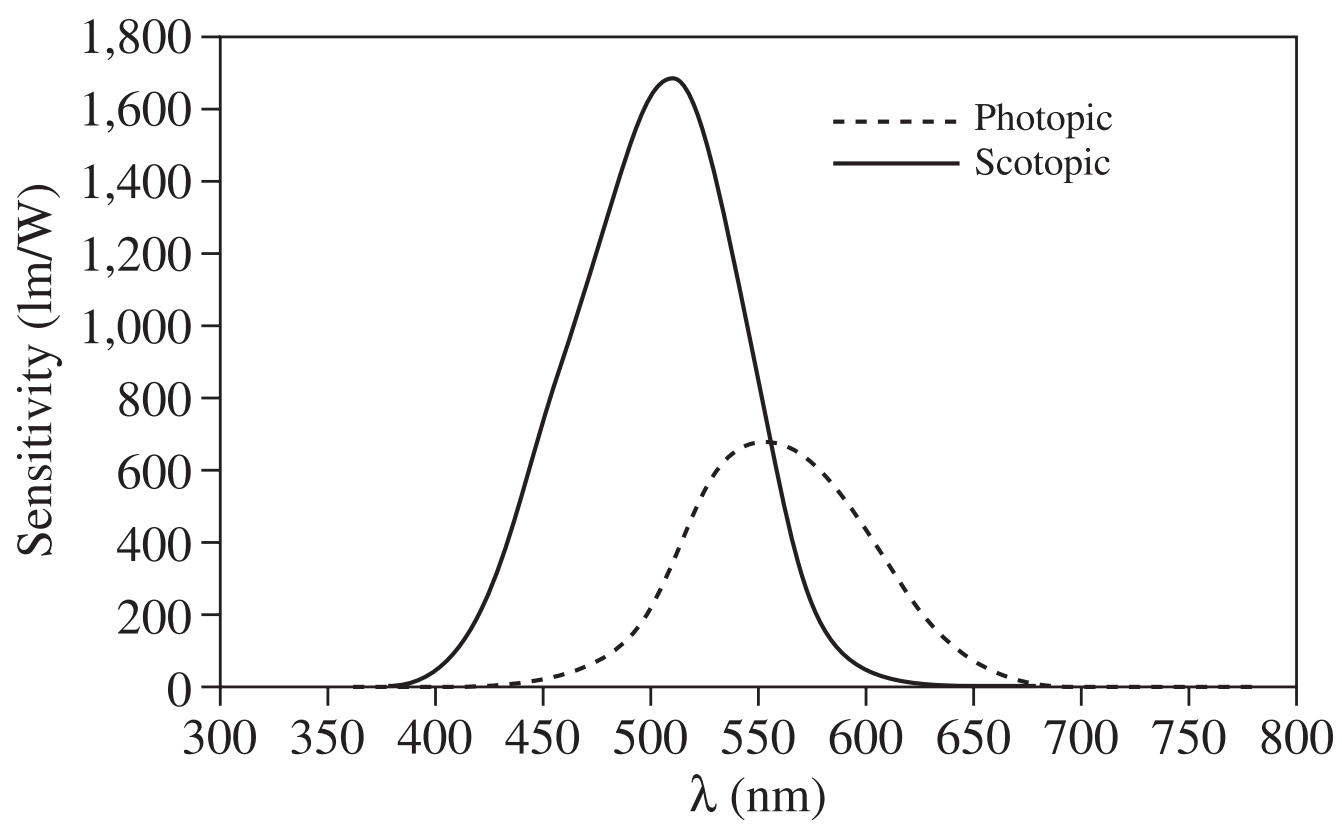

Figure 7.18. Photopic and scotopic sensitivity of the human eye

We note that when our visual system adapts itself to a dark environment, in modifying its sensitivity, our eye becomes more sensitive to the blue portion of the spectrum and its sensitivity increases. It happens that in cities, the available amount of light is often quite small and thus, our visual system works in an intermediate zone called the "mesopic" vision zone. Thus, an intelligent lighting system may benefit from this eye operation. Thus, by reducing the electric power delivered to the lamps during off hours, we save energy, but if the lamp spectrum shifts slightly to blue, our eye will continue to perceive a sufficient amount of light. Consequently, this system saves energy without damaging security conditions in the city. The photos in Figure 7.19 taken in the streets of Albi confirm this observation.
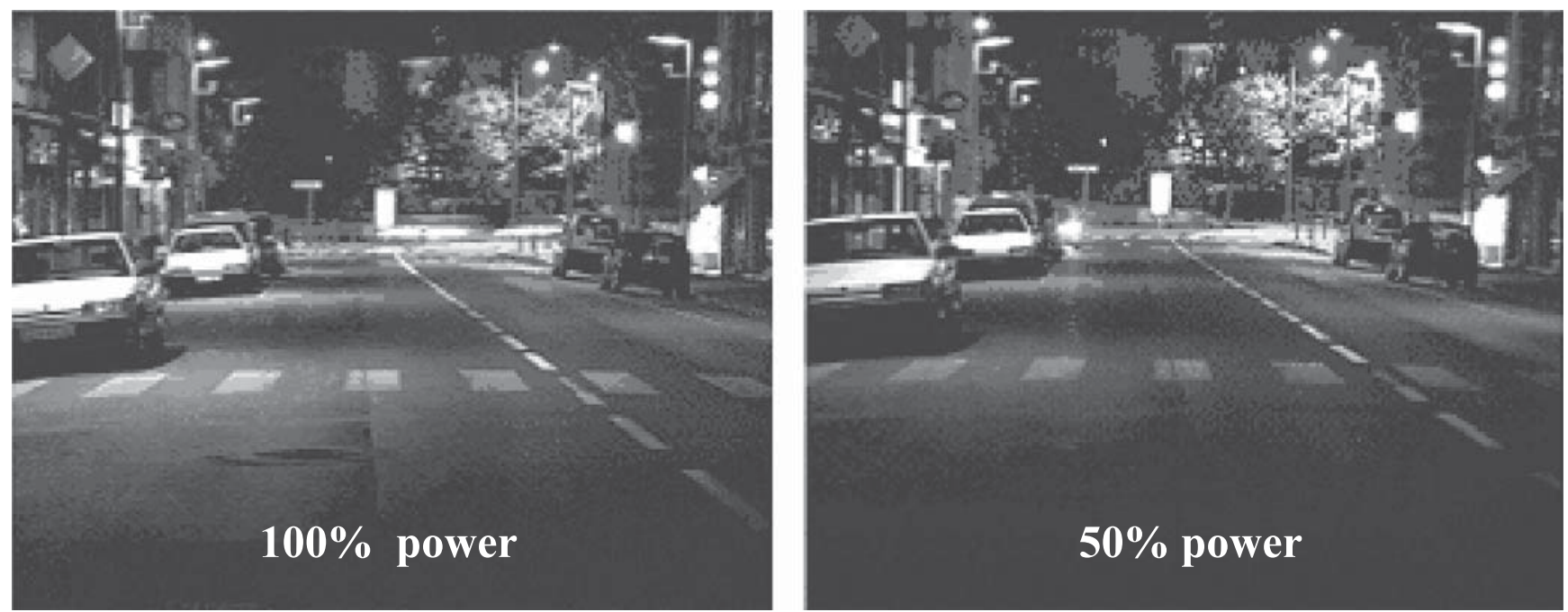

Figure 7.19. Gambetta Avenue in Albi lit by the NumeLiTe system 
On the right of Figure 7.19, the system works at its nominal power, on the left, the electric power is reduced by $50 \%$; the light quantity and quality are more than acceptable.

The first results obtained on the Albi site have demonstrated that at equal energy consumption, the new system generates twice as much light as the previous system. We can thus claim that this system will allow significant energy savings and will then contribute to durable development and land settlement. Our last estimates, based on the first results, show that the NumeLiTe concept may reach energy-saving achievements of about 35-40\% with respect to a traditional system based on sodium lamps with ferromagnetic ballast. These energy savings would correspond to an annual reduction of 800 tons of $\mathrm{CO}_{2}$ per 1,000 luminaries. In extrapolating these results to the European Union, we would save the equivalent of 1.3 million tons of oil in one year!

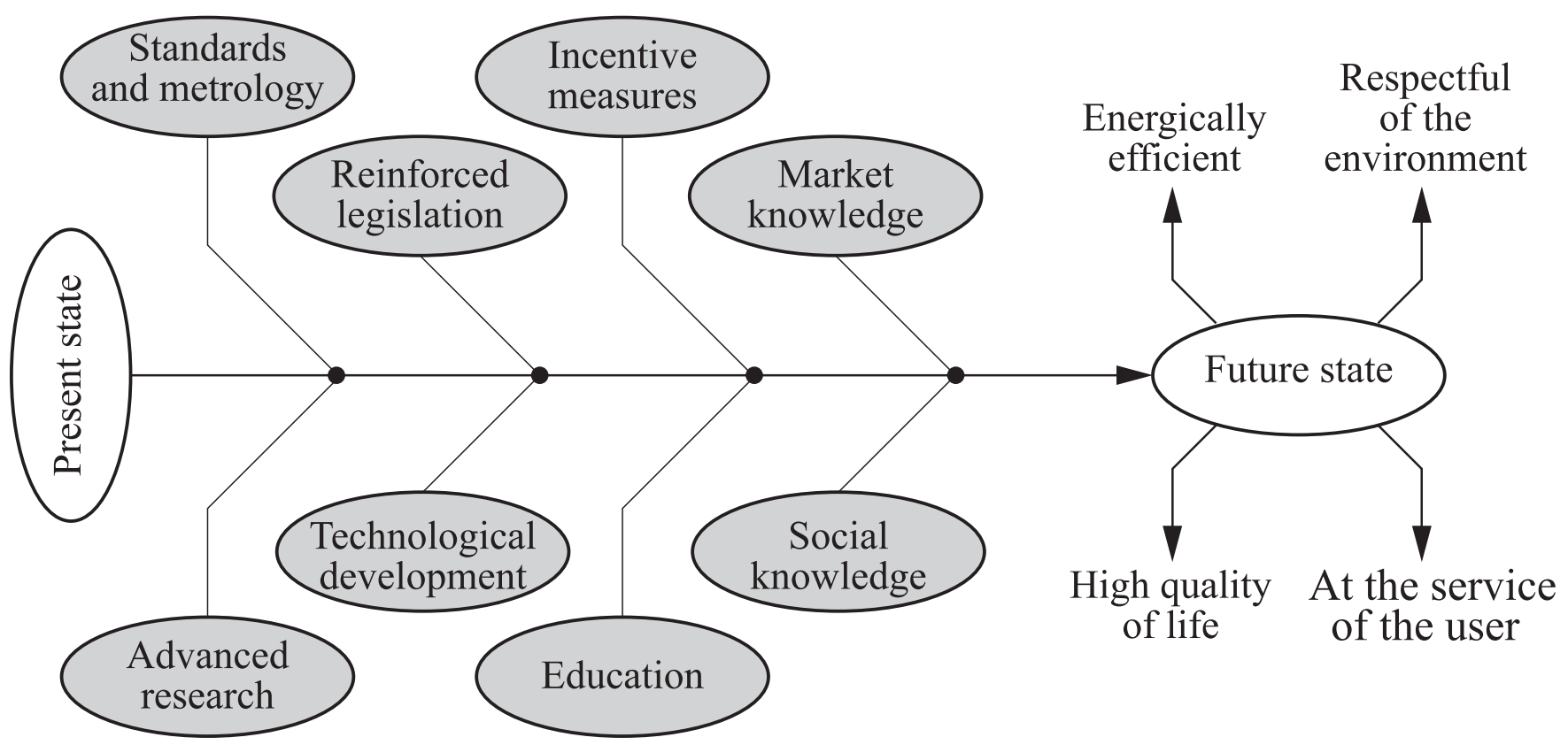

Figure 7.20. How can we satisfy the lighting needs of the future without compromising energy and environmental resources?

\subsection{What is the future for light sources?}

Today, we are certain that the lighting needs of humanity will keep growing; we can expect them to increase by a factor of 2 in the coming two decades. How can we satisfy this increase without the energy demand increasing in the same proportion? This question parties at the very core of sustainable development. Figure 7.20 illustrates in a synoptic way the means we have to find the answer to this question.

Any future lighting system resulting from this process must of course satisfy the light requirements, but it must also respect the energy and environmental resources. 
It must contribute to the quality of life of man and finally it must be at the service of the user. The required qualities increasingly concern the sources' chromatic aspect, their lifetime and their stability (especially chromatic). They also concern their adapted operating conditions (instantaneous lighting and re-lighting, dimensions). The answers are probably, on one hand a better knowledge of the chemistry and the fluid motions in the source, on the other hand the control of the electronics (electrodes or coupling) and the steady-state regime. Finally, better modeling of the source-network interaction and of the ageing of lamps would probably reduce the management cost (in particular the maintenance) of urban, as well as building, lighting networks.

To increase the lifetime of the lamp, to improve its color rendering, to miniaturize the source and the system, to eliminate mercury and the other toxic elements without losing efficiency, etc., these are all interesting challenges for the future.

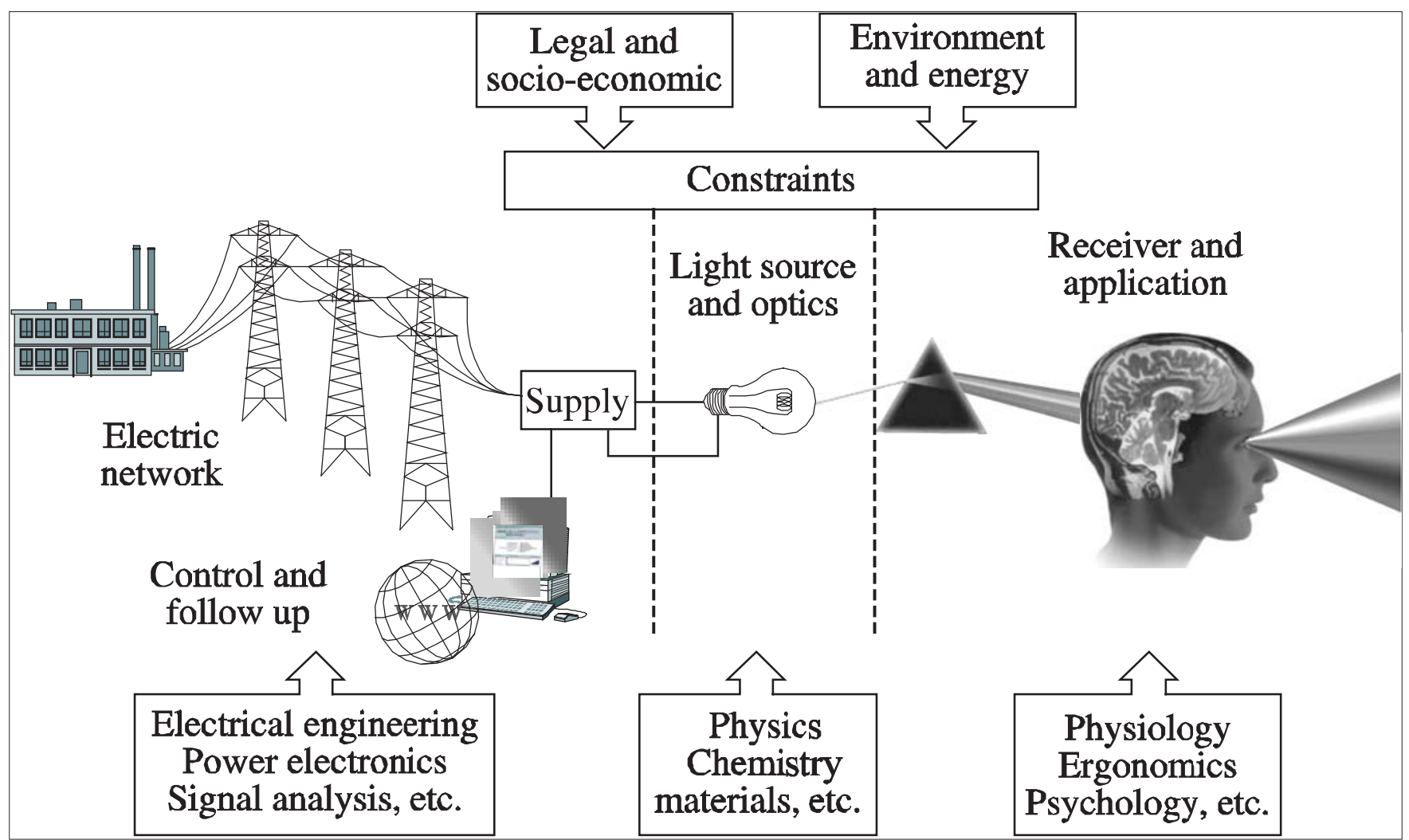

Figure 7.21. The optimization of a light source cannot be realistic without taking into account the complete system from the power source to the photo receiver.

It is a true multi-disciplinal investigation!

However, as shown in Figure 7.21, if we want to win the gamble of a better and more economic light source, which respects the environment and which contributes to improve the quality and comfort of our life, we have to consider all the aspects of 
a complex system and this can only be done through a true a real multi-discipline study.

\subsection{Bibliography}

[ARE 05] ARENSMAN R., "LED market lights up", Electronic Business, Reed Business Information, a division of Reed Elsevier Inc, 4 January 2005.

[EUP 03] EUROPEAN PARLIAMANT AND COUNCIL, "On the restriction of the use of certain hazardous substances in electrical and electronic equipment", Official Journal of the European Union, Directive 2002/95/EC-27/01/2003, 37/19, 2003.

[HAI 02] HAITZ R., KISH F., TSAO J., NELSON J., "Another semiconductor revolution: this time it's lighting", Comp. Semiconductor Magazine, March 2002.

[IAE 05] Data of the International Association for Energy Efficient Lighting, http://www.iaeel.org/, 2005.

[MIL 02] MILLS P., "Why we're here: the \$230-billion global lighting energy bill", Proc. 5th Right Light Conference, p. 369-385, Nice, May 2002.

[OID 02] OPTOELECTRONICS INDUSTRY DEVELOPMENT ASSOCIATION, "Light emitting diodes (LEDs) for general illumination”, OIDA Road Map Update, 2002.

[ROU 07] ROUND H.J., “A note on carborundum”, Electrical World, vol. 49, p. 309, 1907.

[SCO 02] SCHOLAND M., BRODRICK J., PETROW E., "Lighting energy consumption trends and conservation opportunities in US buildings", Presentation to the 1st COST-529 meeting, Toulouse, June 2002.

[ZIS 04] ZISSIS G., "Diodes Electroluminescentes pour l'éclairage”, Techniques de l'Ingénieur, Cahiers Innovation IN-18, p. 1-13, May 2004. 